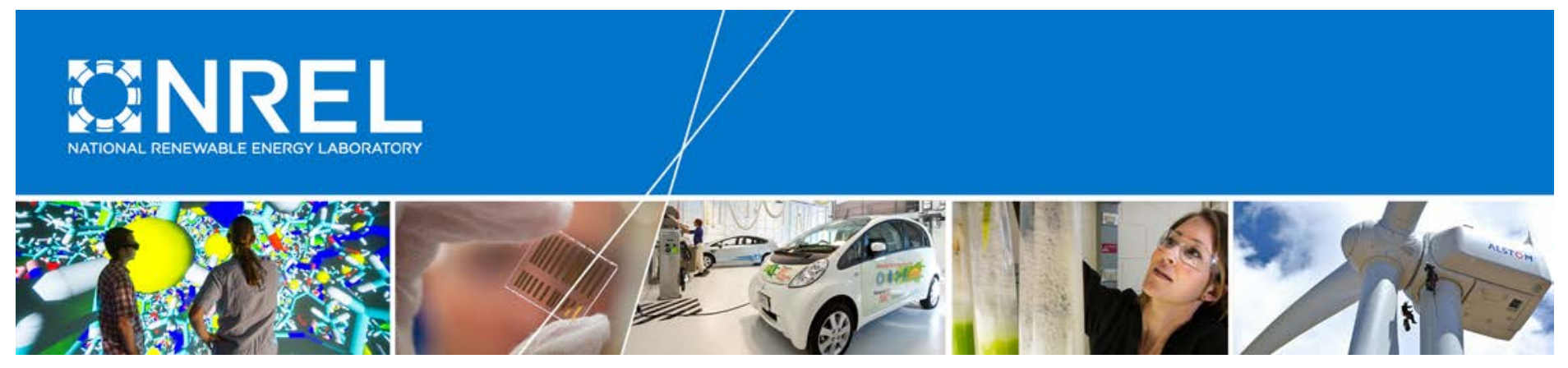

\title{
The Impacts of Changes to Nevada's Net Metering Policy on the Financial Performance and Adoption of Distributed Photovoltaics
}

Pieter Gagnon, Ben Sigrin and Mike Gleason National Renewable Energy Laboratory

NREL is a national laboratory of the U.S. Department of Energy Office of Energy Efficiency \& Renewable Energy Operated by the Alliance for Sustainable Energy, LLC

This report is available at no cost from the National Renewable Energy Laboratory (NREL) at www.nrel.gov/publications.

Technical Report

NREL/TP-6A20-66765

January 2017 


\section{The Impacts of Changes to Nevada's Net Metering Policy on the Financial Performance and Adoption of Distributed Photovoltaics}

Pieter Gagnon, Ben Sigrin and Mike Gleason National Renewable Energy Laboratory

Prepared under Task No. SA15-0940

NREL is a national laboratory of the U.S. Department of Energy Office of Energy Efficiency \& Renewable Energy Operated by the Alliance for Sustainable Energy, LLC

This report is available at no cost from the National Renewable Energy Laboratory (NREL) at www.nrel.gov/publications.

National Renewable Energy Laboratory 15013 Denver West Parkway Golden, CO 80401

303-275-3000 • www.nrel.gov

\section{Technical Report}

NREL/TP-6A20-66765

January 2017

Contract No. DE-AC36-08G028308 


\section{NOTICE}

This report was prepared as an account of work sponsored by an agency of the United States government. Neither the United States government nor any agency thereof, nor any of their employees, makes any warranty, express or implied, or assumes any legal liability or responsibility for the accuracy, completeness, or usefulness of any information, apparatus, product, or process disclosed, or represents that its use would not infringe privately owned rights. Reference herein to any specific commercial product, process, or service by trade name, trademark, manufacturer, or otherwise does not necessarily constitute or imply its endorsement, recommendation, or favoring by the United States government or any agency thereof. The views and opinions of authors expressed herein do not necessarily state or reflect those of the United States government or any agency thereof.

This report is available at no cost from the National Renewable Energy Laboratory (NREL) at www.nrel.gov/publications.

Available electronically at SciTech Connect http:/www.osti.gov/scitech

Available for a processing fee to U.S. Department of Energy and its contractors, in paper, from:

U.S. Department of Energy

Office of Scientific and Technical Information

P.O. Box 62

Oak Ridge, TN 37831-0062

OSTI http://www.osti.gov

Phone: 865.576.8401

Fax: 865.576.5728

Email: reports@osti.gov

Available for sale to the public, in paper, from:

U.S. Department of Commerce

National Technical Information Service

5301 Shawnee Road

Alexandria, VA 22312

NTIS http://www.ntis.gov

Phone: 800.553 .6847 or 703.605 .6000

Fax: 703.605.6900

Email: orders@ntis.gov 


\section{Foreword}

Net energy metering (NEM) is a billing mechanism that has historically compensated owners of distributed generation systems at retail rates for any electricity that they export back to the grid rather than consume on-site. NEM can significantly enhance the financial performance of distributed generation systems from the owner's perspective. For example, a large residential rooftop photovoltaic (PV) system could have a payback period that is 4-8 years shorter if excess generation were credited at the full-retail rate instead of a wholesale electricity rate (Barbose et al. 2016). As of 2016, NEM policy is widespread in the United States-41 states and the District of Columbia have passed legislation mandating full-retail net metering (North Carolina Clean Energy Technology Center 2016).

NEM policies have contributed to the rapid growth of the distributed photovoltaic (DPV) industry in the United States. However, as DPV has reached higher levels of market penetration, a national conversation has begun about the efficacy of full-retail NEM as a means of achieving the diverse objectives of electricity pricing (Hledik et al. 2016; Barbose et al. 2016). Utilities have raised concerns about cost shifting to non-solar customers and utility shareholder profitability. Solar advocates have countered by pointing to a portfolio of studies showing that, at low penetrations and under certain sets of assumptions, the marginal value of solar can be calculated as exceeding the retail rate in some areas (Muro and Saha 2016). Still others describe NEM as a blunt instrument that sends inaccurate price signals to the demand side of the market (King 2015; Kann 2016). Altogether, this conversation has commanded increasing regulatory attention; in the first quarter of 2016 alone, regulators and legislatures revisited NEM policies in 22 states (North Carolina Clean Energy Technology Center 2016).

The following analysis was designed to illustrate the potential impact of NEM policy and tariff changes on the financial performance and adoption of rooftop PV, where a tariff change implemented in early 2016 in Nevada is taken as a case study. Although illustrative of the potential impact that changes to NEM policy could have on the DPV sector, this analysis provides only a partial picture of the context in which these changes are usually made. Other considerations, such as the impacts of NEM policy on the utilities themselves, other electric customers, total renewable energy deployment, and energy sector employment, are not addressed in this study. Nonetheless, the relatively narrow focus of the study allows a more thorough exploration of the interaction of distributed PV and retail electricity tariffs. This methodology provides one component within a broader analytical framework that can be used to inform ongoing and future decisions about NEM policy and the design of tariffs in other states. 


\section{Acknowledgements}

This work was funded by the Office of Strategic Programs of the U.S. Department of Energy's Office of Energy Efficiency and Renewable Energy under contract number DE-AC3608GO28308 with the National Renewable Energy Laboratory (NREL). The authors would like to thank James McCall, Liz Doris, Robert Margolis, Dave Mooney, Gary Schmitz, Robin Newmark, Mary Werner, Gian Porro, and Nate Blair of NREL for their input. We would also like to thank Garrett Weir of the Public Utilities Commission of Nevada for his comments. And, we would like to thank Paul Spitsen, Stephen Capanna, Kevin Lynn, Seungwook Ma, Michele Boyd, and Aaron Bergman of the Department of Energy for their input and reviews. Additionally, the authors would like to thank Kevin Carroll of the Office of Management and Budget for his review and Mike Meshek of NREL for his diligence in editing. 


\section{List of Acronyms}

$\begin{array}{ll}\text { AC } & \text { alternating current } \\ \text { AEO } & \text { Annual Energy Outlook } \\ \text { APR } & \text { annual percentage rate } \\ \text { direct current } \\ \text { DC } & \text { distributed photovoltaic(s) } \\ \text { DPV } & \text { U.S. Energy Information Administration } \\ \text { EIA } & \text { geographic information system(s) } \\ \text { GIS } & \text { Greentech Media } \\ \text { GTM } & \text { gigawatt } \\ \text { GW } & \text { kilowatt } \\ \text { kW } & \text { kilowatt-hour } \\ \text { kWh } & \text { megawatt } \\ \text { MW } & \text { light detection and ranging } \\ \text { Lidar } & \text { net energy metering } \\ \text { NEM } & \text { National Renewable Energy Laboratory } \\ \text { NREL } & \text { public utilities commission of Nevada } \\ \text { PUCN } & \text { photovoltaic(s) } \\ \text { PV } & \text { renewable portfolio standard } \\ \text { RPS } & \text { residential service } \\ \text { RS } & \text { System Advisor Model } \\ \text { SAM } & \text { senate bill } \\ \text { SB } & \text { Typical Meteorological Year 3 } \\ \text { TMY3 } & \text { terawatt-hour } \\ \text { TWh } & \text { watt } \\ \text { W } & \end{array}$




\section{Executive Summary}

Net energy metering (NEM), an instrument for compensating the owners of distributed generation systems, is being revisited nationally as adoption accelerates and markets mature. A modification in Nevada's approach to NEM provided an opportunity to evaluate the potential impacts of changes to the structure of tariffs for customers with distributed generation. This analysis is intended primarily to inform similar decisions in other states.

The legal mandate for the tariff changes in Nevada was Senate Bill (SB) 374. Introduced in March 2015, it instructed Nevada's utilities to develop new NEM tariffs. The bill also granted Nevada's Public Utilities Commission (PUCN) the authority to approve alterations to the charges for NEM customers, specifically stating the PUCN "may authorize a utility to establish just and reasonable charges to avoid, reduce, or eliminate an unreasonable shifting of costs from customer-generators to other customers of the utility" (SB 374 Sec. 2.3.2.d).

NV Energy_-which serves 95\% of Nevada's electric customers - established a new class of tariffs for residential and small commercial NEM customers, which took effect on January 1, 2016. Customers who had already applied for or installed distributed generation have been grandfathered into the previous NEM tariffs. Relative to these previous tariffs, the new NEM tariffs have higher fixed service charges, lower energy consumption charges, and lower credit given for exported electricity. The changes to the tariffs are scheduled to occur in five equally spaced steps over a 12-year period, with the final step occurring in 2028. Although the changes originally applied to any new adopters of distributed generation, a PUCN order re-opened the previous NEM tariffs for up to six megawatts of rooftop PV capacity in NV Energy's northern service territory on January 12017 , exactly one year after the changes first took place.

Our analysis characterizes the impacts of NV Energy's NEM changes in two sections. First, we assess the impact of the new NEM tariffs' design on a photovoltaic (PV) system's payback period. Second, we assess the potential impacts on distributed PV (DPV) deployment by projecting adoption under the new tariffs, and then comparing the results against a counterfactual scenario where the previous full-retail NEM tariffs remained for all customers, with no aggregate capacity limits on DPV deployment.

Our analysis of the impact of the tariff changes for a representative residential customer shows that (1) the increased monthly fixed charge lengthens the payback period of small DPV systems and (2) the decreased credit for exported energy lengthens the payback period of large DPV systems. Acting in concert, these changes significantly reduce the financial performance of DPV of any size for a representative residential customer. We project up to 363 megawatts (MW) of total DPV at the end of 2030 under the new tariffs. By comparison, in 2030 the counter-factual scenario saw up to 1,280 MW of cumulative DPV capacity, 2.2 terawatt-hours (TWh)/year of generation (6.5\% of NV Energy's projected 2030 sales of electricity), and a decrease of $\$ 255$ million annually in NV Energy's gross revenue from bill collection (7.5\% of NV Energy's project 2030 gross revenue from the sale of electricity) compared to what would have been collected if there was no DPV in the state. 


\section{Impact of Fixed Charge Increase and Exported Credit Decrease on DPV} Financial Performance

To explore the relative influence of the changes to discrete components within the tariffs, we modeled the finances of a solar photovoltaic system for a representative residential customer under four tariffs, shown in Table 1. The first (Full-retail NEM) is the previous tariff for residential customers in the Las Vegas region - the Residential Service (RS) tariff-which had full-retail NEM. ${ }^{1}$ The second (Enacted Tariff) is the enacted RS tariff for new NEM customers, modeled at the levels at the end of its scheduled transition. ${ }^{2}$ The third and fourth (Increased Fixed Charge and Reduced Export Credit) are hypothetical tariffs designed to each explore a single component of the Enacted Tariff; each is the same as the original Full-retail NEM tariff, except for having either an increased fixed charge or reduced credit for exported electricity respectively. $^{3}$

Table ES-1. Tariff Structures for Simple Payback Analysis

\begin{tabular}{|c|c|c|c|}
\hline & $\begin{array}{l}\text { Fixed Charge } \\
\text { (\$/mo.) }\end{array}$ & $\begin{array}{l}\text { Energy Consumption } \\
\text { Rate }\left(\$ / \mathbf{k W h}^{\mathrm{a}}\right)\end{array}$ & $\begin{array}{l}\text { Value of Exported } \\
\text { Electricity }(\$ / \mathrm{kWh})\end{array}$ \\
\hline Full-retail NEM & 12.75 & 0.11289 & 0.11137 \\
\hline Enacted Tariff & 38.51 & 0.10179 & 0.02649 \\
\hline Increased Fixed Charge & 38.51 & 0.11289 & 0.11137 \\
\hline Reduced Export Credit & 12.75 & 0.11289 & 0.02649 \\
\hline
\end{tabular}

${ }^{a} \mathrm{kWh}=$ kilowatt-hour

To characterize the financial performance of DPV under each of these tariffs for a representative residential customer, we calculated the simple payback periods for a range of PV systems up to 10.7 kW. ${ }^{4}$ In Figure ES-1 (next page), we can see that the Full-retail NEM tariff has a nearly constant simple payback of 13 years regardless of system size, as the value of electricity is approximately the same whether it is being consumed or exported.

Under the Increased Fixed Charge tariff, there is an automatic increased charge of $\$ 309.12$ annually for switching off the standard tariff. This charge does not change with system size, which results in small systems having long payback periods. As the system size increases, and the increased fixed charges become small relative to the savings from decreased energy purchases, and the payback period converges toward the Full-retail NEM payback period.

\footnotetext{
${ }^{1}$ Historically, NV Energy subtracted several small public purpose charges from the credit that customers received for exported energy. We retained these charges in our modeling, and therefore any mention of nominally full-retail net metering is actually retail less the public purpose charges.

${ }^{2}$ The phased transition results in a gradual change in the financial performance of DPV. We modeled the end levels to explore most clearly the impact of the new NEM tariff design, as opposed to an intermediate step, which would only reflect a partial change.

${ }^{3}$ We designed the hypothetical tariffs to explore the various components' influences on project finances. We are not suggesting that these hypothetical tariffs were viable alternatives or that they reflect the cost of service.

${ }^{4} 10.7 \mathrm{~kW}$ is the size that would result in annual electricity generation equaling annual electricity consumption for the particular customer under consideration.
} 
Moving to the Reduced Export Credit tariff, we can see that it has the same payback as the Fullretail NEM tariff up to $1.7 \mathrm{~kW}$, at which point the system starts exporting electricity for the reduced rate of 2.6 cents $/ \mathrm{kWh}$. As the system size further increases, the payback period under this tariff steadily lengthens, driven by the further increasing fraction of PV generation being exported. $^{5}$

These results allow us to draw a conclusion about the design of the new NEM tariff: the increased fixed charge reduces the financial performance of small systems and the decreased export credit does the same for large systems. When combined in the Enacted Tariff, the result for this representative residential customer is a simple payback period that exceeds 22 years for any size of system. The payback period trends shown are illustrative of the impact of each tariff's structure, but the exact magnitudes should not be interpreted as the current performance of DPV in Nevada - in reality, the tariff will transition to the enacted structure over time, during which the price of PV and cost of electricity will continue to change.

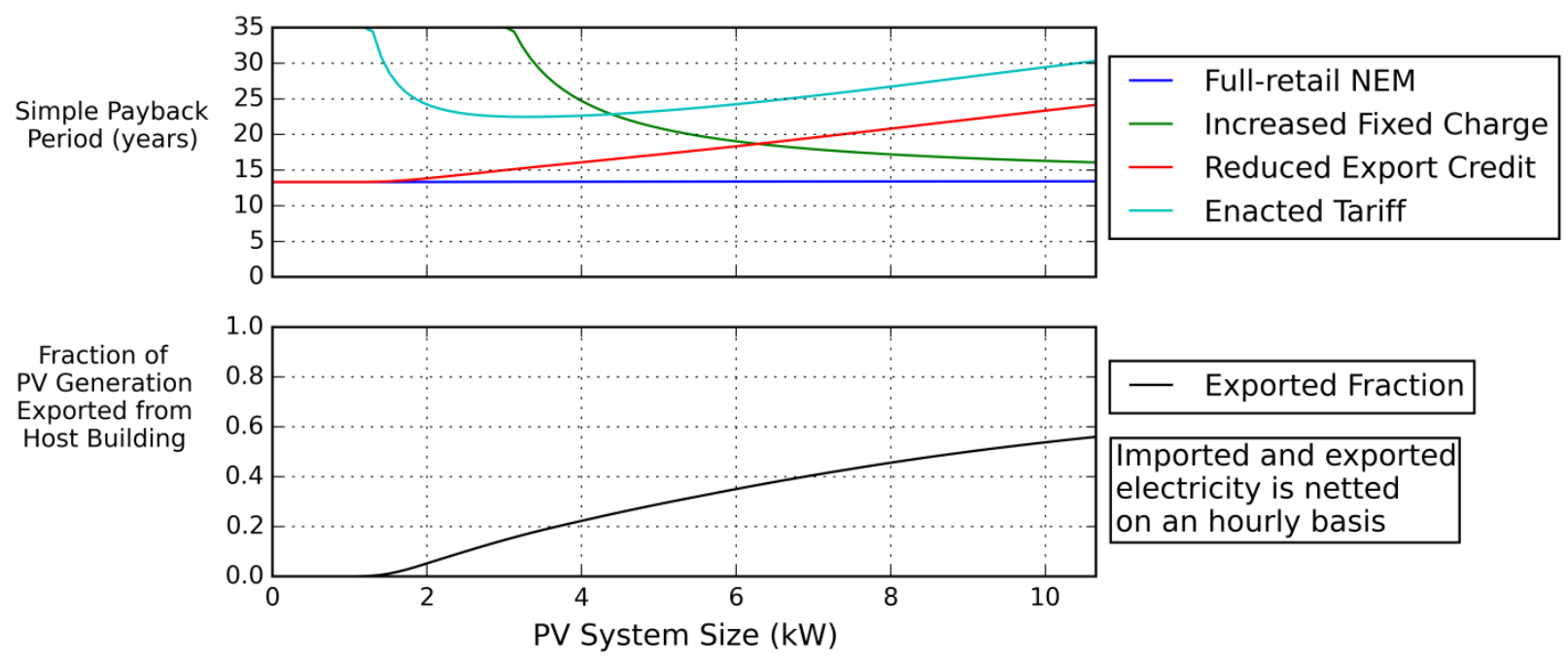

Figure ES-1. Payback period trends under four tariffs for a representative residential customer

\section{Projections of Distributed PV Adoption}

We next used a model of distributed generation adoption, dGen, to project two scenarios: DPV adoption under the new NEM tariffs and a counter-factual scenario where the original tariffs had remained with full-retail NEM and there were no aggregate capacity limits on DPV deployment. ${ }^{6}$ To characterize the sensitivity of the results to different financial conditions, we modeled adoption under both moderate and low PV price declines for each scenario. Note that both the grandfathering of existing DPV customers and the extension of the previous tariffs to six

\footnotetext{
${ }^{5}$ As with the new NEM tariffs implemented in Nevada, the imported and exported electricity is netted hourly not instantaneously.

${ }^{6}$ These Full-retail NEM continuation scenarios are not intended to be a forecast of what would have happened if SB 374 were not enacted, as the levels of DPV adoption seen in those scenarios may have prompted alternative changes in the local retail rate of electricity beyond what is in the current regional forecast. The scenarios should therefore be interpreted as projections of what might have occurred if no action were taken, as opposed to a forecast of what we expect would have happened.
} 
megawatts of capacity in the Northern service territory are reflected in the scenarios with the new tariffs.

We estimate the impact of the new NEM tariffs in terms of total installed DPV capacity, the quantity of the energy generation and exports resulting from that capacity, and the change in the gross revenue collected from DPV customers. We did not evaluate the impact on total installed renewable capacity (such as utility-scale PV), the impact on the operation of the broader Nevada generator fleet, the total net profit implications for NV Energy, or any other considerations of societal cost and benefit. For instance, it should not be assumed that the decreased DPV deployment would necessarily result in less overall PV deployment, especially in light of Nevada's renewable portfolio standard (RPS) and SB 123. ${ }^{7}$ For an exploration of the evolution of Nevada's broader electric sector, see Utility-Scale Solar Deployment Scenarios of the Western United States: Implications for Solar Energy Zones in Nevada (Frew et al. 2016).

Projections of cumulative DPV capacity in NV Energy's territories are shown in Figure ES-2. As discussed previously, the combined effects of the tariff component changes significantly suppressed the financial performance of DPV, lowering the rate of adoption under the new tariffs. In those scenarios, $290 \mathrm{MW}-363 \mathrm{MW}$ of cumulative DPV are projected in 2030. For reference, $226 \mathrm{MW}$ of DPV had been installed in Nevada as of the end of the second quarter of 2016, with $93 \mathrm{MW}$ installed in 2015 alone (GTM and SEIA 2016). ${ }^{8}$ In contrast, the cumulative capacity of DPV was projected to be 1,100 MW-1,280 MW by 2030 under the Full-retail NEM continuation scenarios, depending on the rate at which PV prices were assumed to fall. A pause in adoption in the year 2022 was projected in all scenarios, caused by the ITC decreasing from $22 \%$ to $0 \%$ for residential customers at that time.

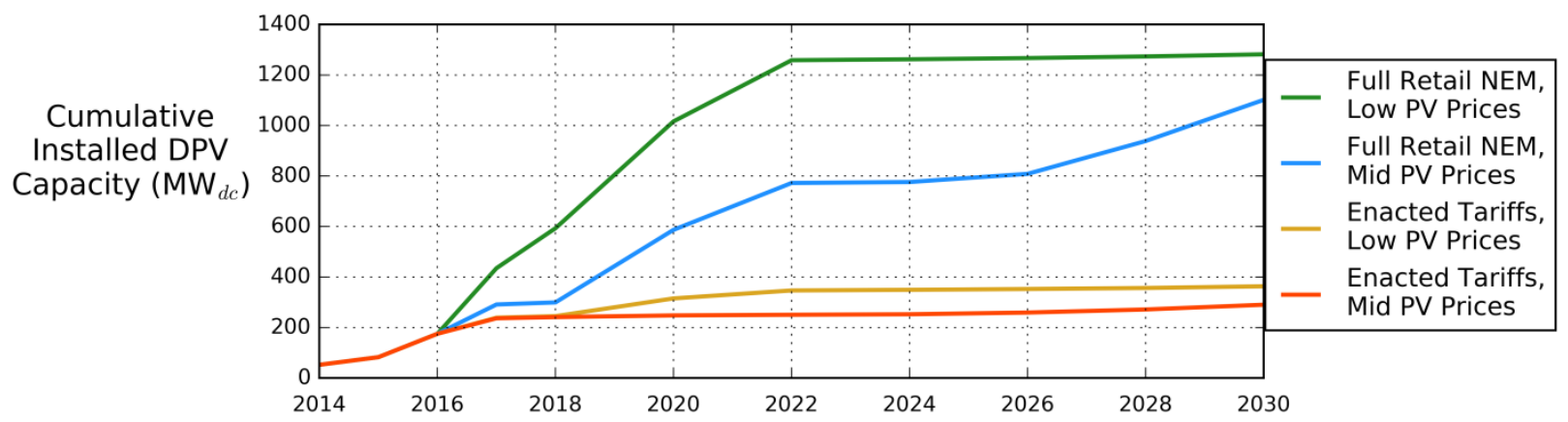

Figure ES-2. Projections of cumulative installed DPV capacity

\footnotetext{
${ }^{7}$ Nevada's RPS calls for $25 \%$ of electricity sold by NV Energy to come from renewable generation by 2025 , with $6 \%$ of that required to come from solar. SB 123 mandates the retirement of $800 \mathrm{MW}$ of coal-fired generation by 2019 and the procurement of $350 \mathrm{MW}$ of capacity from renewable energy facilities.

${ }^{8}$ The increase in capacity during 2016 is largely due to contracts that were signed prior to the tariff changes. The projected slowdown in installations in 2017 is already indicated in a decrease in applications-there were only 14 new applications in July of 2016, in contrast to a peak of 2,958 in August of 2015 (NV Energy RenewableGenerations 2015, NV Energy RenewableGenerations 2016).
} 
To place the magnitude of this DPV capacity in context, the resulting electricity generation under the new tariffs would be $0.5 \mathrm{TWh} /$ year to $0.6 \mathrm{TWh} /$ year in 2030 . That is $1.4 \%-1.8 \%$ of the 34.2 TWh of electricity projected to be sold by NV Energy in $2030 .{ }^{9}$ In contrast, under the Full-retail NEM tariffs and without aggregate capacity limits, between 1.9 and $2.2 \mathrm{TWh} /$ year of electricity generation from DPV was projected in 2030, which is $5.7 \%-6.5 \%$ of NV Energy's projected electricity sales in 2030.

The final impact we explored is the decrease in NV Energy's gross revenue from bill collection from DPV customers as compared to what would have been collected if there were no DPV. This calculation includes the grandfathered DPV that will remain on the full-retail NEM tariffs. It is important to note that a decrease in revenue does not equate to a change in profit, which would also require a determination of the change in costs incurred by NV Energy. The net influence of the DPV systems on the cost of electricity for all of NV Energy's customers is particularly sensitive to the differential between the decrease in revenue from the DPV relative to the cost of energy from other renewable sources, as Nevada's RPS and Senate Bill 123 both require further quantities of renewable energy be procured.

The decrease in gross revenue for the four scenarios is shown in Figure ES-3. The decrease was projected to be $\$ 222$ million-\$255 million (in real 2016 dollars) per year in 2030 in the scenarios where full-retail NEM was continued. ${ }^{10}$ For reference, that is $6.5 \%-7.5 \%$ of the $\$ 3,395$ million (real 2016 dollars) of total gross revenue projected to be collected by NV Energy in 2030 for the sale of electricity. ${ }^{11}$

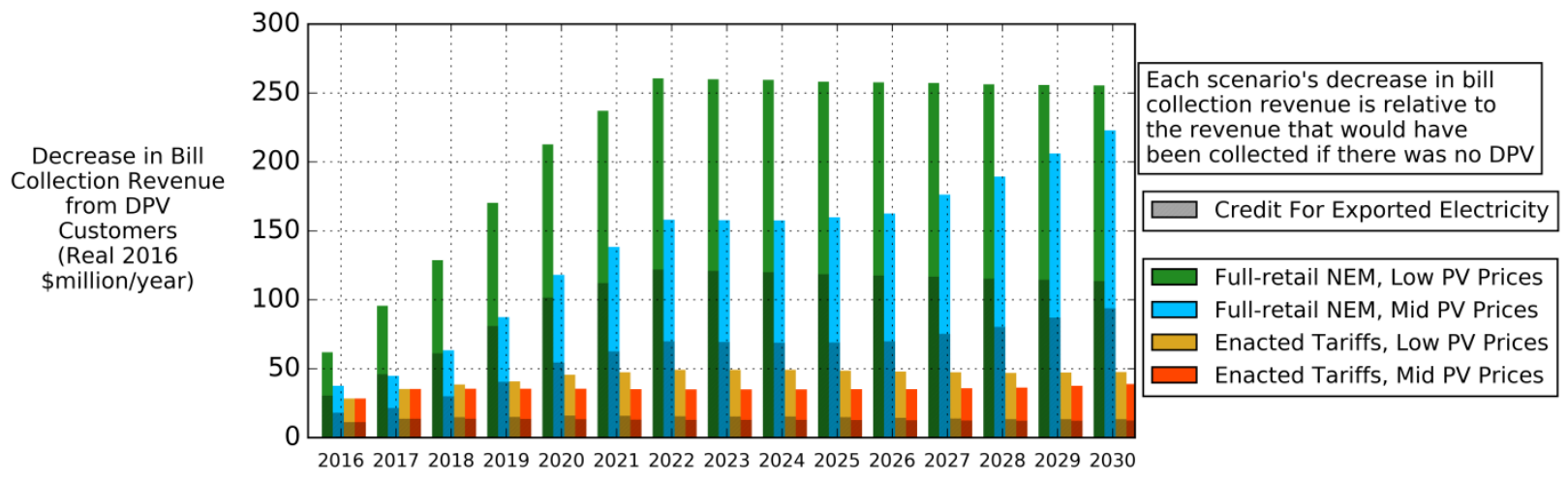

Figure ES-3. Projections of the decrease in gross utility bill collection revenue from DPV customers, relative to gross revenue under no DPV adoption

\footnotetext{
${ }^{9}$ This projection of the electricity to be sold by NV Energy in 2030 was obtained by increasing the 29.21 TWh that NV Energy reported selling in 2014 by the $17 \%$ increase in the consumption of electricity that the EIA's Annual Energy Outlook (AEO) projects for the Mountain Census Division from 2014 to 2030 (FERC 2014A FERC 2014B EIA 2015).

${ }^{10}$ The decrease in gross revenue is a combination of PV's influence on energy consumption and reduced demand charges, increased collection from fixed charges, and the value of credit earned for exported generation.

${ }^{11}$ NV Energy reported collecting $\$ 3,056.5$ million from the sale of electricity in 2014 (FERC 2014A and FERC, 2014B). A projection of 2030 gross revenue collection was obtained by multiplying the projected change in price of electricity and the projected change in electricity consumption of each of the residential, commercial, and industrial sectors, and combining them into a weighted-average increase. The electricity price and consumption projections came from the EIA's AEO reference case for the Mountain Census Division (EIA 2015).
} 
The result of dividing the reduction in gross revenue by the amount of generation could be taken as the average cost at which NV Energy would procure this particular resource. For example, the Enacted Tariffs scenario with low PV prices saw 0.61 TWh generated and a $\$ 48$ million reduction in gross revenue in 2030, which equates to an effective cost of 7.9 cents $/ \mathrm{kWh}$ of procured DPV generation. The 7.9 cents $/ \mathrm{kWh}$ is the average compensation across both grandfathered systems and new systems without full-retail NEM. In contrast, the Full-retail NEM scenario with low PV prices saw 2.2 TWh of generation and a gross revenue reduction of $\$ 255$ million, which equates to an effective cost of 11.6 cents $/ \mathrm{kWh}$ of procured DPV generation.

Although this metric is useful for a rough characterization of the relative costs of procurement, in most cases it would be inappropriate to use the metric alone to compare the cost of DPV generation with that of other energy sources without considering other values. For instance, DPV has additional value of reduced transmission and distribution losses relative to utility-scale $\mathrm{PV}$, and additional costs relative to dispatchable generation such as natural gas turbines. 


\section{Table of Contents}

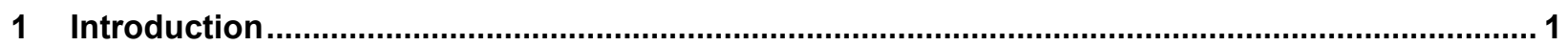

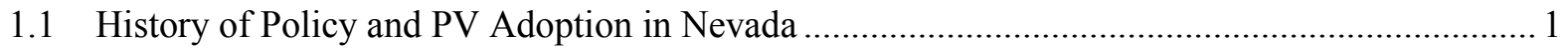

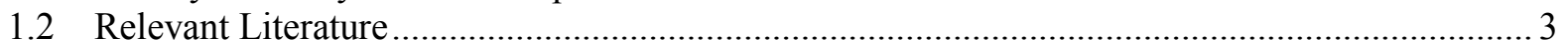

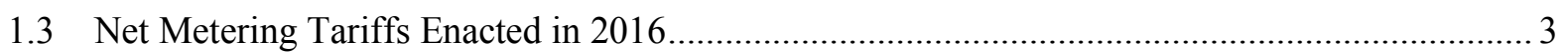

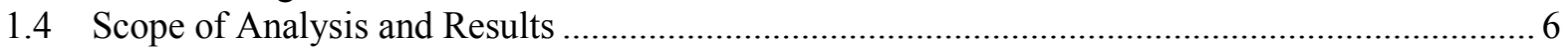

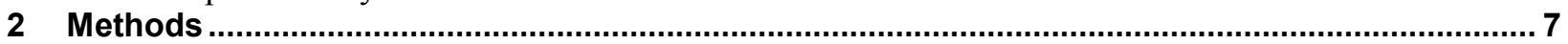

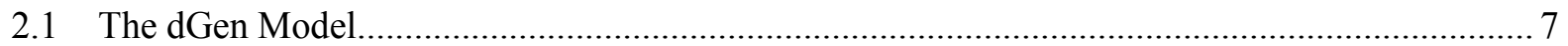

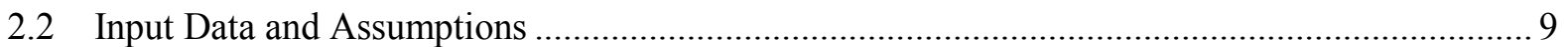

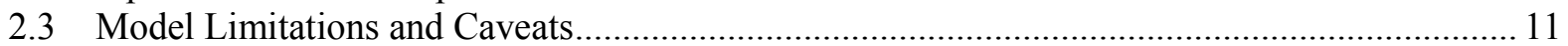

3 Impact of Changes in Fixed Charge and Excess Generation Credit on DPV

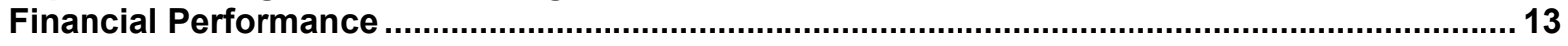

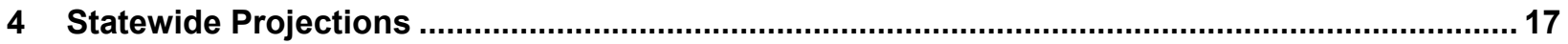

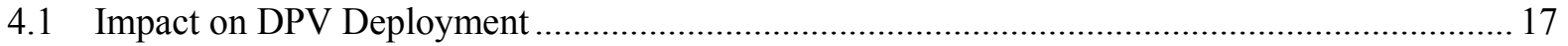

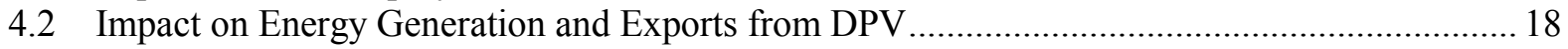

4.3 Impact on Gross Revenue Collection from DPV Customers ................................................. 19

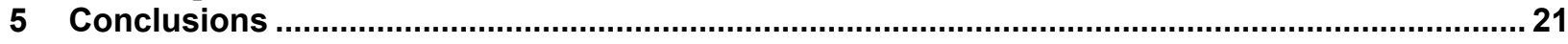

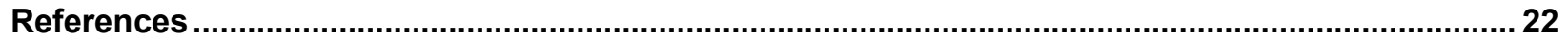




\section{List of Figures}

Figure ES-1. Payback period trends under four tariffs for a representative residential customer ...............vi

Figure ES-2. Projections of cumulative installed DPV capacity ............................................................vii

Figure ES-3. Projections of the decrease in gross utility bill collection revenue from DPV customers, relative to gross revenue under no DPV adoption.............................................................. viii

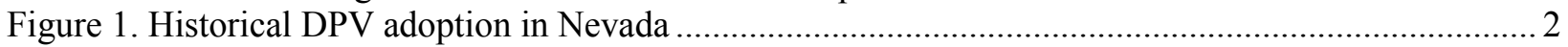

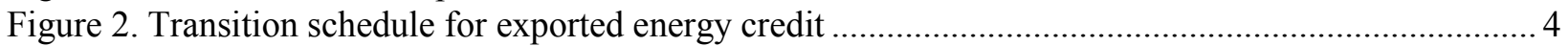

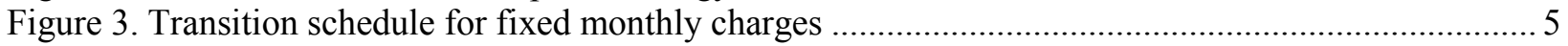

Figure 4. Transition schedule for energy consumption charges ....................................................... 5

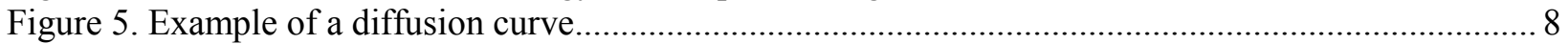

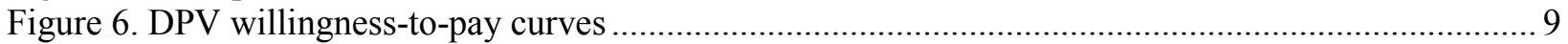

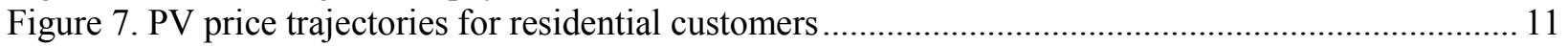

Figure 8. PV price trajectories for non-residential customers........................................................... 11

Figure 9. Financial performance of DPV systems under four different tariffs .................................... 16

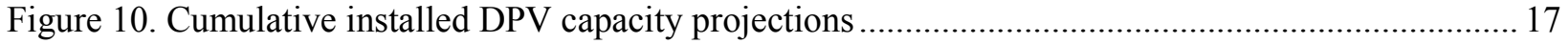

Figure 11. Projections of annual energy generated by DPV systems ….............................................. 18

Figure 12. Projections of energy exported from DPV host buildings .................................................... 18

Figure 13. Projections of decrease in gross utility bill collection revenue from DPV customers.............. 20

\section{List of Tables}

Table ES-1. Tariff Structures for Simple Payback Analysis................................................................... v

Table 1. Non-NEM Tariff Component Levels as of May 2016 ............................................................ 5

Table 2. Tariff Structures for Simple Payback Analysis....................................................................... 14 


\section{Introduction}

\subsection{History of Policy and PV Adoption in Nevada}

Nevada's original net energy metering (NEM) law for renewable energy systems was enacted in 1997 (DSIRE 2016A). Prior to the recent legislative action, the it required Nevada's electric utilities to offer net metering to their customers up to an aggregate capacity equal to $3 \%$ of the total peak capacity of all utilities in the state. In June 2013, the Nevada Legislature required the Public Utilities Commission of Nevada (PUCN) to open an investigation to evaluate the costs and benefits of NEM and to subsequently recommend a methodology for allocating such costs and benefits appropriately (Assembly Bill 428). ${ }^{12}$ The PUCN commissioned E3, a consulting firm, to perform that investigation (Price et al. 2014).

On September 26, 2014, the PUCN submitted its NEM report to the Nevada Legislature. This document recommended that the legislature modify existing net metering statutes to provide the PUCN greater latitude in addressing net metering issues in general rate cases. An investigation under Docket 14-06009 was also initiated to examine the implications of creating a separate customer class for net-metered customers.

On March 17, 2015, Senate Bill 374 - the legal impetus for the tariff changes explored in this analysis - was introduced in the Nevada Senate. ${ }^{13}$ The bill temporarily set the cumulative capacity of NEM systems at $235 \mathrm{MW}$, and it instructed Nevada's utilities to develop new net metering tariffs to be approved by the PUCN. Specifically, it stated that the PUCN "may authorize a utility to establish just and reasonable charges to avoid, reduce, or eliminate an unreasonable shifting of costs from customer-generators to other customers of the utility" (SB 374 Sec. 2.3.2.d). This language echoes that of similar legislative action in other states, where rapidly increasing adoption of DPV has raised concerns about cost shifting to non-solar customers and reduced utility shareholder profitability.

NV Energy filed applications with the PUCN for approval of a marginal cost-of-service study in July 2015. The results of the study were ultimately used to inform the structure of a new class of net metering tariffs. These new tariffs, described in Section 1.2, were established on December 23,2015 , and they took effect on January 1, 2016. There is no statutory or regulatory limit on the cumulative capacity of DPV systems under the new tariffs.

The introduction of the new NEM tariffs originally included a scheduled transition of five annual step changes in the levels of each of the tariff's components. On February 17, 2016, the PUCN issued a modified order that lengthened the transition period to twelve years by making each step change last three years, with the final levels reached at the beginning of 2028. Additionally, the original implementation of the new NEM tariffs applied them to all distributed generation customers. This was retroactively changed on September 16, 2016, when the PUCN approved the grandfathering of approximately 32,000 customers who had either already installed or had pending applications for distributed generation systems prior to the change in the tariffs. Further,

\footnotetext{
${ }^{12}$ See https://www.leg.state.nv.us/Session/77th2013/Bills/AB/AB428_EN.pdf.

${ }^{13} \mathrm{See}$ https://www.leg.state.nv.us/Session/78th2015/Bills/SB/SB374_EN.pdf.
} 
a PUCN order reopened the original tariffs to six megawatts of rooftop PV capacity on January 1 2017.

Separate from net metering regulations, Nevada has the RenewableGenerations incentive program, which was established in 2003 as a result of Assembly Bill $431{ }^{14}$ The incentive amounts changed in steps based on the amount of cumulative capacity in the state. As of July 2016 , the program was on its ninth step, and had paid \$203 million out of its \$255 million cap (NV Energy RenewableGenerations 2016). The ninth step offered $\$ 0.1475 / \mathrm{W}_{\mathrm{AC}}$ for systems under $25 \mathrm{~kW}$ and $\$ 0.0159 / \mathrm{kWh}$ for five years for systems over $25 \mathrm{~kW}$.

Nevada established a renewable portfolio standard (RPS) in 1997. It requires NV Energy to use eligible renewable energy sources to supply a minimum of $25 \%$ of the total electricity that it sells by 2025 , including a $6 \%$ annual requirement from solar. The actual installed capacity could be compliant at slightly lower levels, as energy from DPV capacity that was installed prior to 2015 is counted with a 2.4 multiplier. Additionally, Senate Bill 123 requires NV Energy to retire 800 MW of coal-fired plants by December 31, 2019. As part of the replacement of that capacity, a minimum of $350 \mathrm{MW}$ must come from renewable energy facilities (DSIRE 2016B).

Historical trends in the cumulative installed capacity of DPV in Nevada are shown in Figure 1 (GTM and SEIA, 2016). Significantly reduced system prices and a maturing solar industry resulted in rapid adoption in the residential sector in both 2014 and 2015 . The continued installation of systems during 2016 is largely due to contracts that were signed prior to the tariff changes. A slowdown in installations in 2017 is indicated in a decrease in applications to the RenewableGenerations incentive program - there were only 14 new applications in July of 2016, in contrast to a peak of 2,958 in August of 2015 (NV Energy RenewableGenerations 2015, NV Energy RenewableGenerations 2016). As of March 2016, Nevada was ranked fifth amongst all states in total PV, with 1,240 MW of installed capacity (GTM and SEIA, 2016). Over 80\% of that capacity came from utility-scale installations.

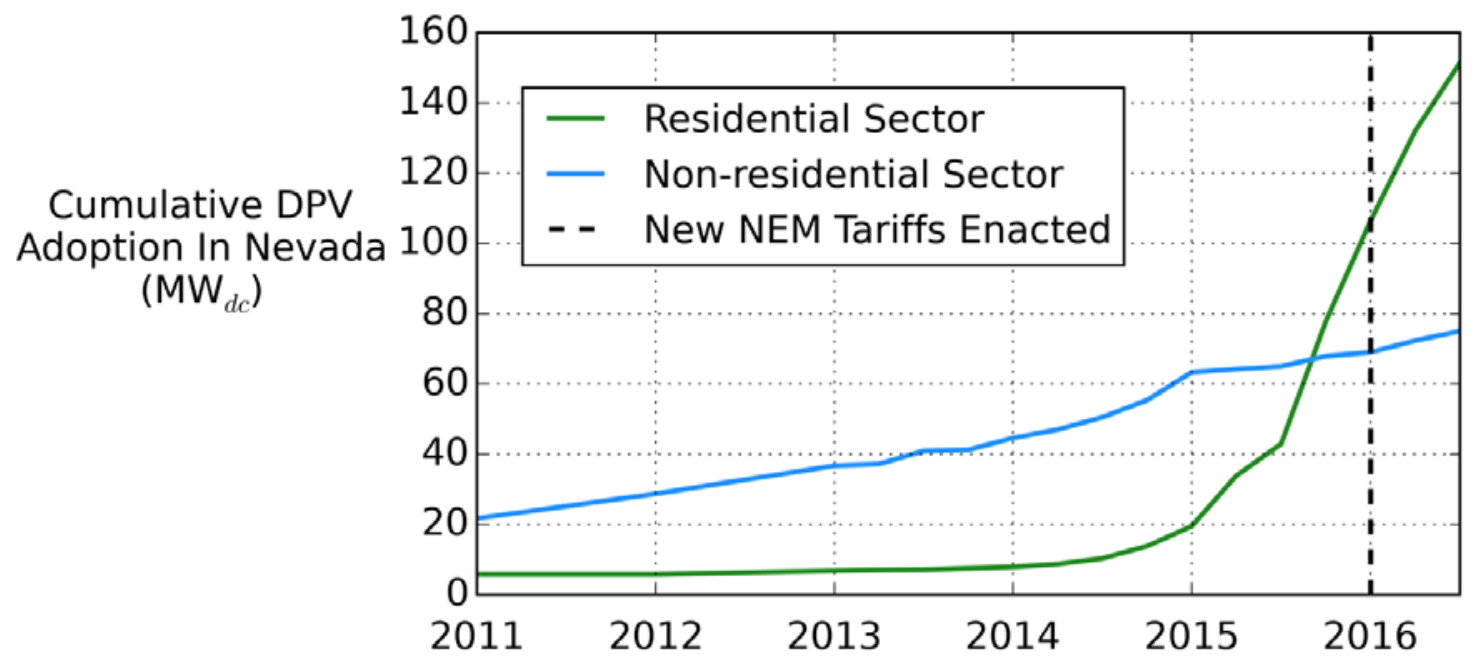

Figure 1. Historical DPV adoption in Nevada

\footnotetext{
${ }^{14}$ For more information, see https://www.nvenergy.com/renewablesenvironment/renewablegenerations/.
} 


\subsection{Relevant Literature}

Over time, our understanding of the opportunities and challenges associated with DPV has steadily increased - and with it, the body of literature supporting this area. The following selection of recent publications may be useful for individuals and organizations making decisions about DPV and net metering.

- Costs and Benefits of DPV: The costs and benefits of DPV vary depending on its location within the electric grid. See Methods for Analyzing the Benefits and Costs of Distributed Photovoltaic Generation to the U.S. Electric Utility System (Denholm et al. 2014) for a discussion of the suite of tools that can be used for this evaluation.

- Impact on the Distribution System: An important consideration in the adoption of large quantities of DPV is its effects on the distribution system. See Emerging Issues and Challenges in Integrating Solar with the Distribution System in the On the Path to SunShot series (Palmintier 2016) and Distribution Systems in a High Distributed Energy Resources Future: Planning, Market Design, Operation and Oversight in the Future Electric Utility Regulation Report Series (De Martini, Kristov, and Schwartz 2015).

- Revenue and Regulatory Considerations: Beyond the technical aspects of the distribution system, large amounts of DPV could also influence utility-customer interactions, cost recovery, and revenue streams. See Utility Regulatory and Business Model Reforms for Addressing the Financial Impacts of Distributed Solar on Utilities in the On the Path to SunShot series (Barbose et al. 2016) and Regulatory Considerations Associated with the Expanded Adoption of Distributed Solar (Bird et al. 2013).

- Distributed Resource Compensation: Looking ahead, tariffs could evolve in many ways. See Distribution System Pricing with Distributed Energy Resources in Future Electric Utility Regulation Report Series (Hledik, Lazar, and Schwartz 2016), for a discussion of four potential approaches for compensating distributed resources.

- Recovery of Fixed Costs: The design of rates is a multi-objective optimization that seeks to balance economic efficiency, equity and fairness, customer satisfaction, utility revenue stability, and customer price and bill stability. See Recovery of Utility Fixed Costs: Utility, Consumer, Environmental and Economist Perspectives in the Future Electric Utility Regulation Report Series (Wood et al. 2016) for a discussion of cost recovery from four different perspectives.

\subsection{Net Metering Tariffs Enacted in 2016}

SB 374 allowed the PUCN to approve separate classes for NEM customers, meaning new netmetered customers would have different retail electricity tariffs than other customers. Approximately 95\% of Nevada's electric customers are served by NV Energy (EIA 2015), which has different tariffs for service territories in the northern and southern parts of the state. The territories are derived from the historical entities of Sierra Power and NV Power, which merged in 1999. This analysis considers only the DPV adoption in NV Energy's service territories, not the rural electricity providers in the rest of the state. 
The new classes for net-metered customers include residential and small commercial entities. ${ }^{15}$ Medium and large commercial entities in both territories can still net meter their systems through riders, which specify that exported electricity earns a credit equal to the cost of electricity at that time minus several small public purpose charges. The value of exported electricity is typically less important to large commercial entities, as they tend to self-consume most or all of their DPV generation.

The estimated generation from distributed systems may not exceed $100 \%$ of the customer's annual energy consumption under both the new and the original tariffs, because allowing selfgeneration was the original objective. Systems up to $1 \mathrm{MW}$ in capacity are generally eligible for NEM, although systems greater than $25 \mathrm{~kW}$ may be subject to certain costs at the utility's discretion. In contrast to the previous limit of 3\% of peak capacity, there is no aggregate capacity limit of net-metered systems under the new tariffs.

The new tariffs will undergo a phased transition to their final levels. The original schedule released on December 23, 2015 had annual step changes over a five-year period. A modified order on February 17, 2016 kept the same steps but lengthened each step to three years, for a total transition period lasting 12 years. Each step will see an increase in the fixed service charges, a decrease in the credit given for exported electricity, and a decrease in energy consumption charges. ${ }^{16}$ The scheduled transitions for five of the tariffs are shown in Figure 2 through Figure 4. ${ }^{17}$ These tariff changes do not apply to customers who had installed a system or had a pending application prior to January 12016 . Additionally, six megawatts of rooftop PV capacity in the Sierra Pacific service territory can subscribe to the previous tariffs.

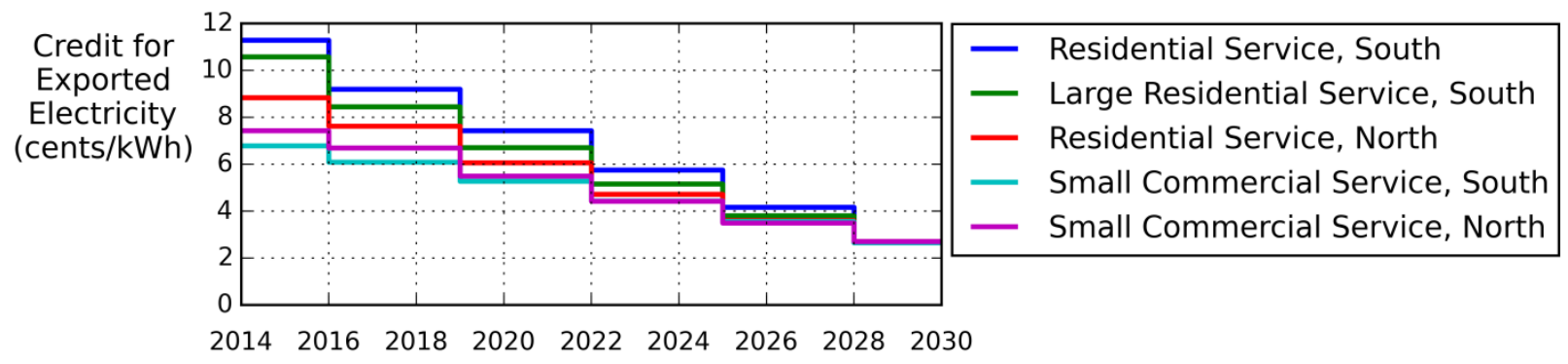

Figure 2. Transition schedule for exported energy credit

\footnotetext{
${ }^{15}$ A commercial entity is considered "small" based on different criteria in the two service territories. In the south, its consumption must not exceed 3,500 $\mathrm{kWh}$ in any one month, and in the north, its peak demand must be less than $50 \mathrm{~kW}$ and energy consumption less than $10,000 \mathrm{kWh} / \mathrm{month}$. For reference, a representative 2,500 - $\mathrm{ft}^{2}$ quick-service $^{2}$ restaurant would consume approximately $17,000 \mathrm{kWh} / \mathrm{month}$, which exceeds the limits of both tariffs.

${ }^{16}$ Except for the small commercial General Service tariff in the south, which has increasing, instead of decreasing, consumption charges.

${ }^{17}$ Several time-of-use tariffs are also available. These tariffs were incorporated in the analysis, but are not shown here.
} 


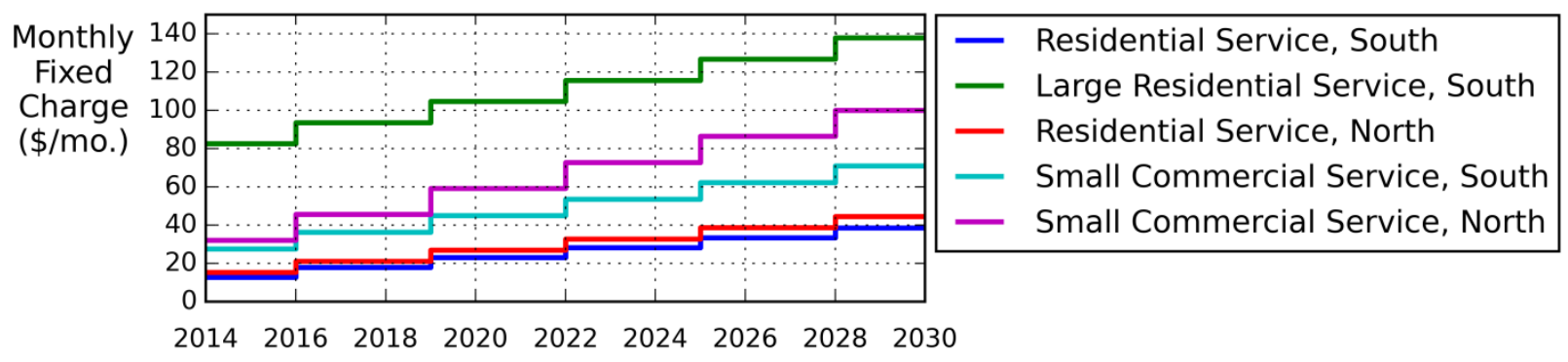

Figure 3. Transition schedule for fixed monthly charges

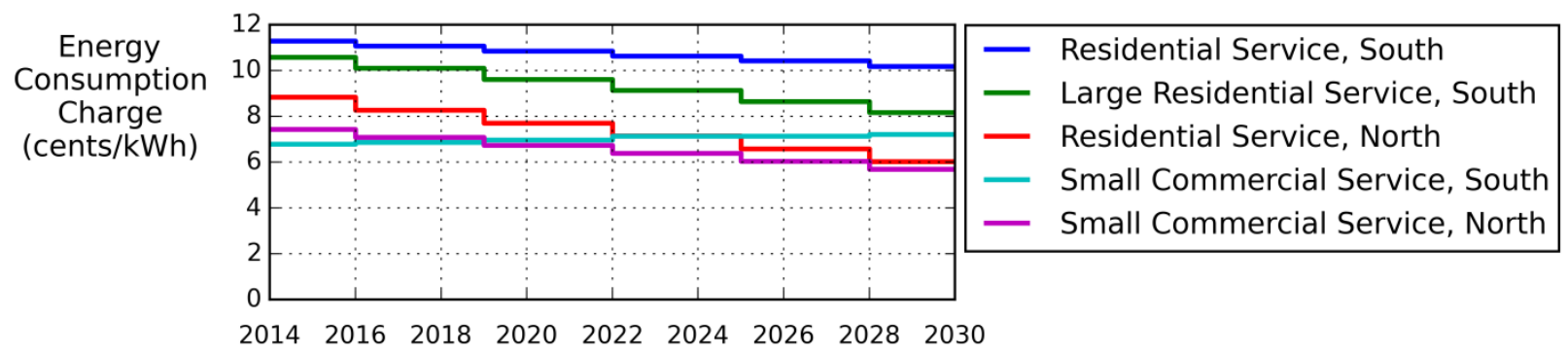

Figure 4. Transition schedule for energy consumption charges

The equivalent tariffs for non-NEM customers are shown in Table 2. These are the levels as of May 2016; they will be adjusted quarterly with each Base Tariff Energy Rate adjustment and Deferred Energy Accounting Adjustment.

Table 1. Non-NEM Tariff Component Levels as of May 2016

\begin{tabular}{lllll}
\hline Rate Class & $\begin{array}{l}\text { Rate } \\
\text { Code }\end{array}$ & Territory & $\begin{array}{l}\text { Fixed Basic Service } \\
\text { Charge }(\$ / m o .)\end{array}$ & $\begin{array}{l}\text { Energy Consumption } \\
\text { Charge (\$/kWh) }\end{array}$ \\
\hline Residential Service & RS & South & $\$ 12.75$ & $\$ 0.1083$ \\
Large Residential Service & LRS & South & $\$ 82.50$ & $\$ 0.1012$ \\
General Service & GS & South & $\$ 27.50$ & $\$ 0.0635$ \\
Domestic Service & D-1 & North & $\$ 15.25$ & $\$ 0.0851$ \\
Small General Service & GS-1 & North & $\$ 32.00$ & $\$ 0.0711$ \\
\hline
\end{tabular}

Note that under the new NEM tariffs, electricity imports and exports are netted hourly. Therefore, a customer effectively receives credit at the retail rate for each $\mathrm{kWh}$ of electricity exported to the grid, up to the amount of utility-delivered electricity that the customer receives during each hour-long interval. Any excess exported electricity in each hour is then credited at the rates shown in Figure 2. To align with this, exported electricity is calculated on an hourly basis throughout this report. 


\subsection{Scope of Analysis and Results}

This analysis focuses on the impact of tariff design on DPV adoption and financial performance, with the primary goal being to inform ongoing and future NEM decisions across the United States. To that end, we used the recent changes in NEM tariffs prompted by Nevada SB 374 as a case study. We used NREL's customer adoption model (dGen) to analyze two scenarios: (1) projections of DPV adoption under the new NEM tariffs and (2) a counter-factual scenario where the original tariffs remained in effect, with full-retail NEM and no aggregate capacity limit on DPV deployment.

Critically, in the counter-factual scenarios that model a continuation of full-retail net metering, we assumed no change in the structure or level of future retail tariffs, other than linearly scaling the tariffs with the projected change in the price of electricity in the EIA 2015 AEO Reference Case for the Mountain Census Division. Reality could deviate from this assumption as DPV adoption increases, the bulk power system evolves, and legislative priorities change. Therefore, the full-retail NEM scenarios should be interpreted as projections of what might have occurred if no action were taken, as opposed to a forecast of what we expect would have happened.

We evaluated the impact of the new NEM tariffs in terms of total installed DPV capacity, the quantity of the energy generation and exports resulting from that capacity, and the impact on the gross revenue collected from DPV customers. We did not evaluate the impact on total installed renewable capacity (such as utility-scale PV), the impact on the operation of the broader Nevada generator fleet, the total net profit implications for NV Energy, or any other considerations of societal cost and benefit. For instance, it should not be assumed that the decreased DPV deployment would necessarily result in less overall PV deployment, especially in light of Nevada's RPS and SB 123. ${ }^{18}$ Nor should it be assumed that the decrease in gross revenue collected from DPV customers would translate one-to-one into a loss for NV Energy, as the final resulting profit impact depends on multiple factors, including savings from avoided fuel purchases, the cost of operating the grid with the DPV, changes in infrastructure investment, and other such factors.

As previously emphasized, this study is narrowly focused on the interaction of DPV and retail tariffs - it is not intended to be a holistic assessment of the criteria by which tariff design and policy choices are made. Studies that aim to provide a more comprehensive assessment for the particular case of Nevada include Nevada Net Energy Metering Impacts Evaluation 2016 Update (Price et al. 2016) and Distributed Energy Resources in Nevada (SolarCity and NRDC 2016). Lastly, a broader exploration of the evolution of Nevada's electric sector can be found in UtilityScale Solar Deployment Scenarios of the Western United States: Implications for Solar Energy Zones in Nevada (Frew et al. 2016)

\footnotetext{
${ }^{18}$ Nevada's RPS calls for $25 \%$ of electricity sold by NV Energy to come from renewable generation by 2025 , with $6 \%$ of that required to come from solar. SB 123 mandates the retirement of $800 \mathrm{MW}$ of coal-fired generation by 2019 and the procurement of $350 \mathrm{MW}$ of capacity from renewable energy facilities.
} 


\section{Methods}

The results of our projections are shown in terms of total installed DPV capacity, the quantity of the energy generation and exports resulting from that capacity, and the change in the gross revenue collected from DPV customers. These metrics were selected to characterize trends within the DPV sector itself, separate from the broader system. By focusing on these metrics, it is easier to draw more general conclusions about the potential impacts of tariff changes on the adoption of DPV, and extend them to other states. In contrast, a complete cost benefit analysis or overall renewable energy deployment would be highly specific to the policy objectives and electrical system of Nevada.

A customer adoption model, dGen, with supporting techno-economic analysis of a representative system was chosen to obtain the desired metrics, as described below. Such a method could be utilized in any administrative region to assess the implications of a change in compensation for distributed generation technologies.

\subsection{The dGen Model}

The projections made in this analysis were performed with NREL's dSolar model, which is part of the greater dGen family of models. ${ }^{19}$ This family of models projects behind-the-meter adoption of distributed generation technologies for residential, commercial, and industrial entities in the contiguous United States. The dGen model is a successor to NREL's SolarDS model (Denholm, Drury, and Margolis 2009), which was used to model DPV adoption in the SunShot Vision Study (DOE 2012) and the Renewable Electricity Futures Study (Mai et al. 2012).

dGen projects the adoption of PV based on the "diffusion of innovations" framework popularized by Bass (1969) and Rogers (2003). This framework theorizes that novel technologies "diffuse" into populations following a logistic pattern: early adopters, mass adoption, and late adopters. An example diffusion pattern is shown in Figure 5. Rather than assuming all potential PV customers are rational profit-maximizing agents who immediately adopt a profitable technology, the framework posits that a novel technology diffuses through a population of potential customers based on the financial attractiveness of the investment. The technology never diffuses completely through an entire population, as there is always a fraction of consumer for whom the technology is not relevant or beneficial.

\footnotetext{
${ }^{19}$ Documentation of the dGen model can be found in Sigrin et al. (2015). Additional information can be found at http://www.nrel.gov/analysis/dgen/.
} 


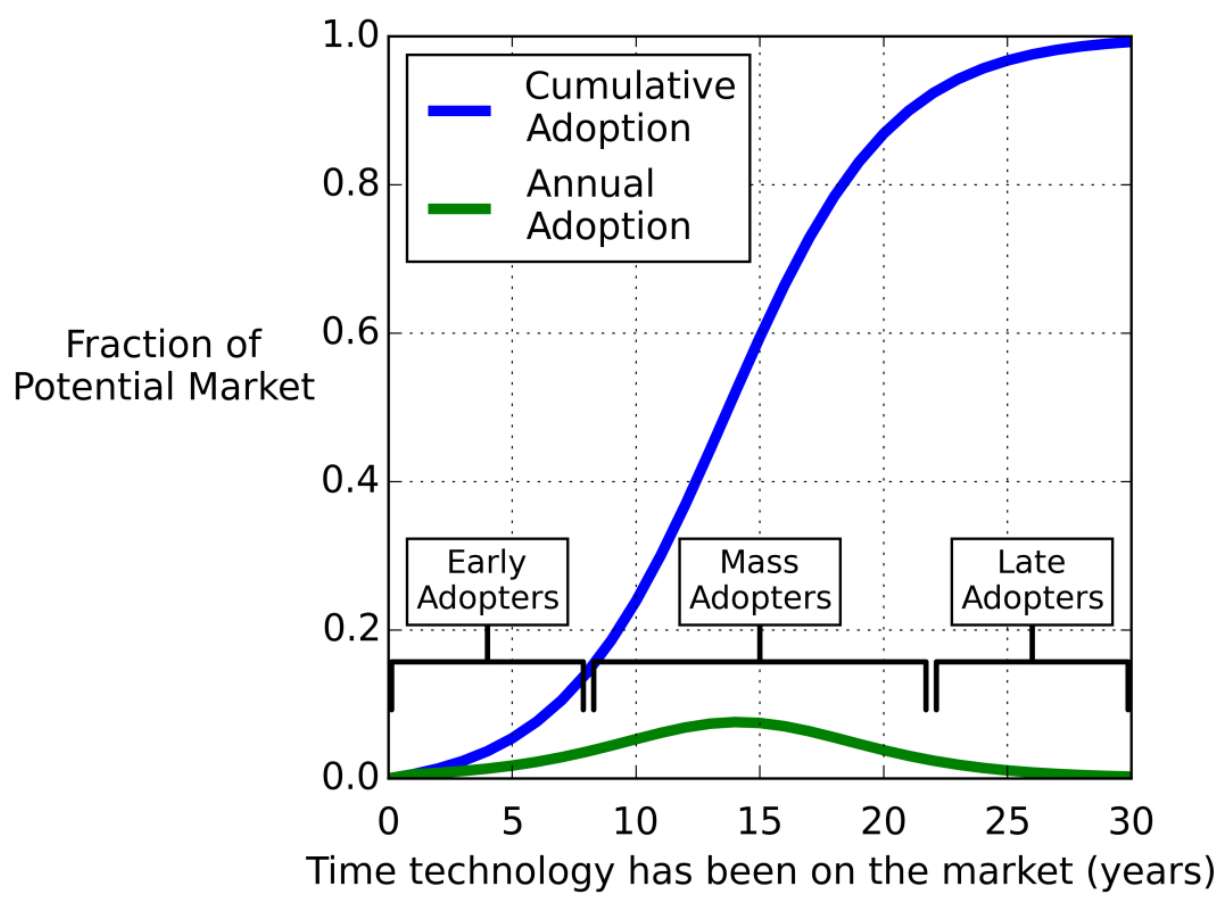

Figure 5. Example of a diffusion curve

dGen generates thousands of statistically representative agents to model potential adopters of DPV across the residential, commercial, and industrial sectors. Each agent has an assumed energy consumption profile, roof area, and other techno-economic attributes that are representative of the underlying population heterogeneity. DPV finances are recalculated for each of the agents in each of the model's bi-annual solve years. The model determines the optimal PV system size that maximizes the net present value of the agent's investment in DPV. ${ }^{20}$

After determining the financial attractiveness of a project for each agent, the model estimates the fraction of potential customers who would be willing to adopt the technology as a function of the financial attractiveness (Figure 6). For example, we can see that with a 15 -year payback, $12 \%$ of possible residential customers and $1 \%$ of possible commercial and industrial customers would be willing to adopt D PV.

\footnotetext{
${ }^{20}$ When agents evaluate systems, they are constrained by their own total consumption as well as the roof area available to them; therefor, dGen estimates the technical potential of rooftops within Nevada, as well as representing NV Energy's limitation of a net-metered system to $100 \%$ of a customer's annual consumption. This system sizing functionality is an addition to dGen that is not described in the documentation (Sigrin et. al. 2016).
} 


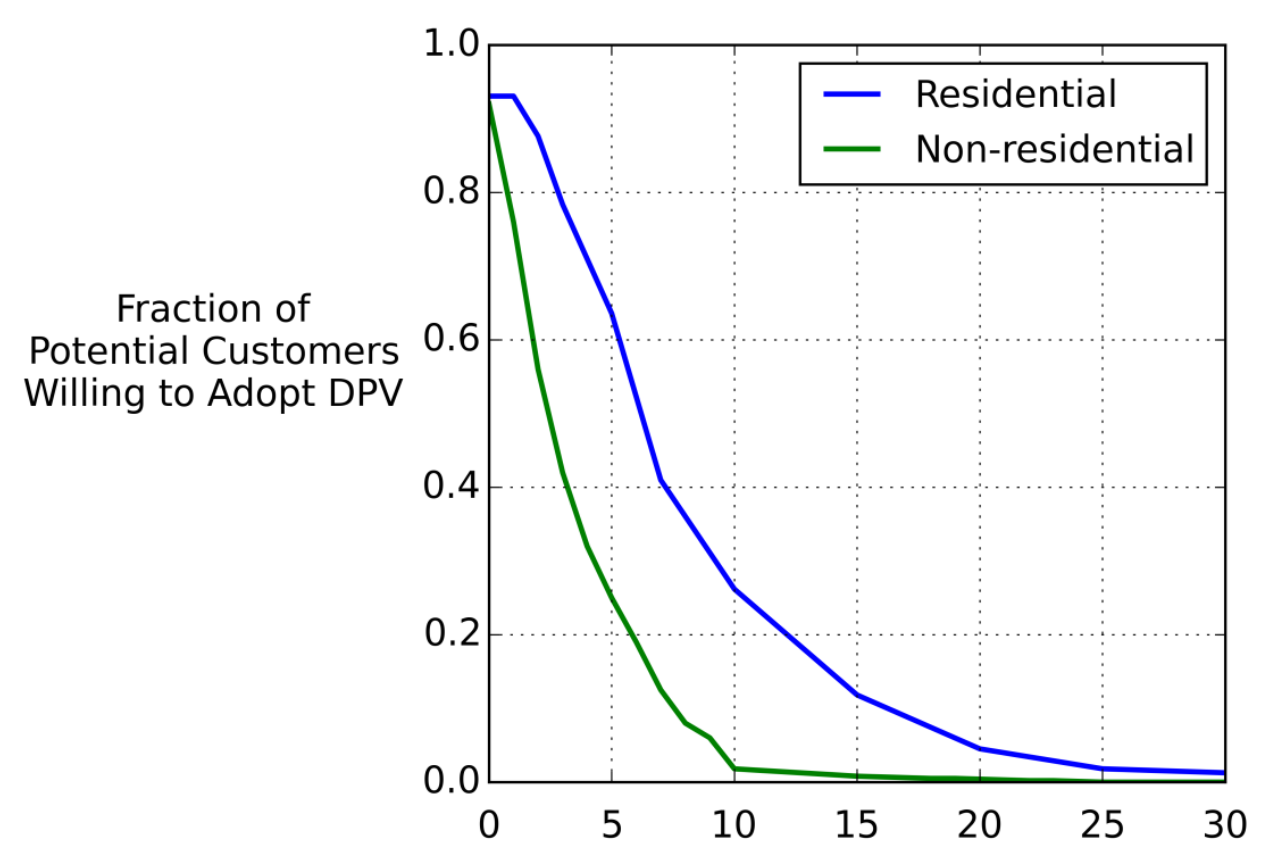

Figure 6. DPV willingness-to-pay curves

This approach assumes that financial performance is the primary driver of DPV adoption, and it captures the non-financial considerations of customers. For example, even with long payback periods that would achieve lower rates of return than other potential investments, we would still expect a small percentage of possible customers to adopt PV. Conversely, even if the payback period were zero years - meaning the bill savings of PV exceed the financing payments - we would still expect to find a small number of eligible customers to be uninterested in adopting.

dGen updates the shape and magnitude of the S-curve as a result of the aggregation of each of the agents' willingness to pay for DPV, projecting the diffusion of the technology through the population as conditions change over time.

\subsection{Input Data and Assumptions}

Except where otherwise stated, a base set of assumptions is shared across the four scenarios we modeled. This narrative of the key assumptions summarizes the more complete description in the dGen documentation (Sigrin et al. 2016).

- Retail Rates: All of the retail tariffs offered by NV Energy as of May 2016 were represented in the model. Each modeled agent (representing potential customers) evaluated the bill savings of DPV by comparing the lowest-cost electricity tariff available to them with PV against the lowest-cost electricity tariff available to them without PV. Applicability requirements, such as minimum or maximum average peak demand, were enforced. The tariffs were assumed to scale with the change in the price of electricity for each sector projected for the Mountain Census Division in the EIA AEO 2015 reference case.

- Electricity Load and Growth: The EIA's Residential Energy Consumption Survey (EIA 2009) microdata were used to generate representative demand for electricity in the residential sector. The EIA's Commercial Building Energy Consumption Survey (EIA 2012) microdata 
were used to generate equivalent representative demand for electricity in the commercial and industrial sectors. The number of potential DPV customers was assumed to scale with load growth projections for each sector for the reference case of the AEO 2015 projections for the Mountain Census Division.

- Policy: The federal investment tax credit was represented as it was scheduled in the legislative action of December 2015, meaning it was assumed to phase down to $10 \%$ for nonresidential entities and $0 \%$ for residential entities by $2022 .{ }^{21}$ The Modified Accelerated Cost Recovery System schedule is represented, including the scheduled phase-out of the first-year bonus depreciation by 2020. Nevada's RenewableGenerations incentive program was assumed to expire after the current step - the ninth step, which has a capacity of $75 \mathrm{MW}$ was completed. The ninth step has an Expected Performance Based Buydown of \$0.1475/W and a performance-based incentive of $\$ 0.0159 / \mathrm{kWh}$ for five years.

- Rooftop Availability and Characteristics: Adoption in the residential sector was restricted to owner-occupied detached buildings. Trends in the characteristics of the rooftops (e.g., slope, azimuth, and the typical fraction of area that is suitable for PV deployment) follow the distributions observed in an analysis of lidar data performed by NREL (Gagnon et al. 2016).

- Market Growth: Bass diffusion parameters were calibrated by historical data of PV adoption in Nevada through 2015 (GTM and SEIA 2016).

- System Design: For every bi-annual solve year, each modeled agent in dGen re-evaluated what PV system size would maximize the net present value of their investment. Maximum system sizes were constrained both by the quantity of suitable roof area of each particular agent, as well as the capacity that would provide $100 \%$ of annual energy consumption. The rate of adoption was therefore driven by the financial returns of optimally sized systems. In order to capture the small fraction of customers who are willing to adopt PV even if it did not pay itself off over time, customers defaulted to evaluating a system sized to meet $100 \%$ of their annual consumption if no size PV system had a positive net present value. ${ }^{22}$ Due to the small fraction of customers willing to adopt with long payback periods, this assumption had little impact on total installed capacity.

- Financing: We assumed residential customers financed their systems with a 15 year, 5\% real Annual Percentage Rate (APR) loan, with $80 \%$ debt fraction. This was modeled after the state's PowerSavers loan program. We assumed commercial and industrial entities took a 20 year, 5.25\% (real) APR loan, with 80\% debt fraction. We assumed residential customers have a $10 \%$ real discount rate, and commercial and industrial customers have a $12 \%$ real equity rate.

- PV Cost Trajectories: The two PV price trajectories were based on the 'Mid' and 'Low' projections from the 2015 Annual Technology Baseline (NREL 2015), shown in Figure 7 and Figure 8. The cost of PV in each county was further adjusted by regional capital cost multipliers for utility-scale PV plants (EIA 2013).

\footnotetext{
${ }^{21}$ Due to the investment tax credit's Commence Construction clause, dGen assumes non-residential deployment can obtain the credit of the year prior to the completion of its construction.

${ }^{22}$ The distribution of residential customers' willingness to pay for PV was constructed from survey data (Sigrin et al. 2014).
} 


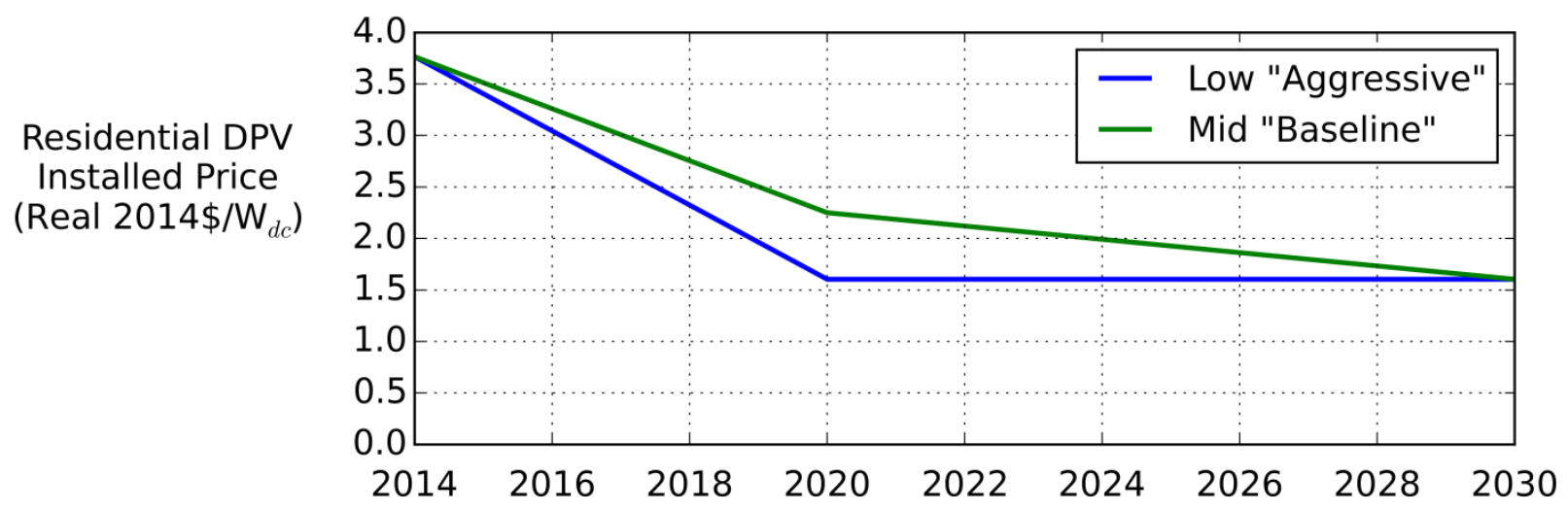

Figure 7. PV price trajectories for residential customers

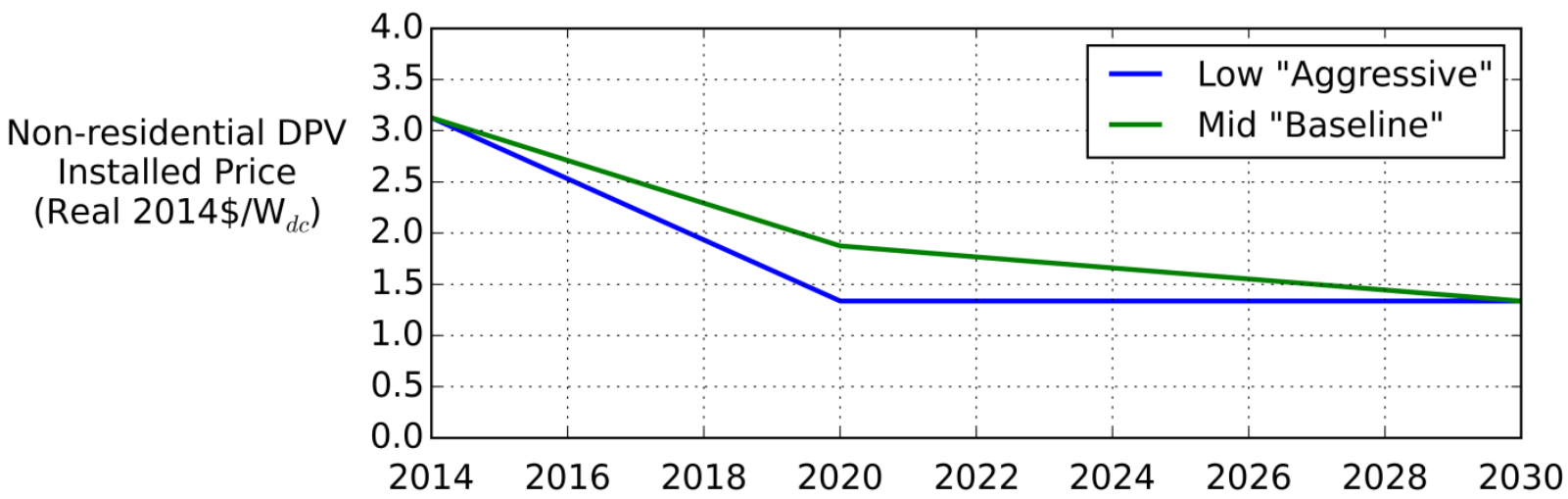

Figure 8. PV price trajectories for non-residential customers

\subsection{Model Limitations and Caveats}

As do all customer adoption models, dGen necessarily includes some simplifications. Listed here are some key limitations that result from these simplifications.

- No Complementary Technology Representation: We did not represent any enabling technologies or load shifting behavior, such as energy storage or smart appliances, which would enable a DPV owner to increase self-consumption of PV generation.

- Unconstrained Rate of Installation: We did not assume any limitations on the rate at which PV could be installed in the state, nor the dynamics of system pricing due to an abundance or lack of competition amongst installers. The greatest amount of annually installed capacity projected was $211 \mathrm{MW}$ per year 2019-2020. For reference, slightly more than $100 \mathrm{MW}$ of DPV capacity were installed in Nevada during 2015, primarily in the residential sector (GTM and SEIA 2016). 
- No Complex Tariff Evolution: All existing elements within tariffs were simply scaled based on the AEO's projections for the change in the retail cost of electricity. This did not capture the potential for more complex tariff changes to reflect the evolution of the bulk power system. For example, solar deployment increases in all of NREL's 2015 Standard Scenarios, which may suppress the energy consumption charges of midday hours for time-of-use tariffs. $^{23}$

- Accurate Estimates of Bill Savings: We assumed that the agents estimate payback as rational actors with foresight. Due to the increase in complexity from the declining tariff schedules, customers may incorrectly estimate their potential bill savings in later years.

${ }^{23}$ For more information about the Standard Scenarios, see http://www.nrel.gov/analysis/data tech baseline.html. 


\section{Impact of Changes in Fixed Charge and Excess Generation Credit on DPV Financial Performance}

As described in Section 1.3, the three components in the NEM tariffs were changed relative to their non-NEM counterparts. All the new tariffs have increased fixed charges and decreased compensation for exported electricity. All the tariffs except the small commercial tariff in the southern territory have decreased energy consumption charges.

Critically, the increase in fixed charges only applies to the new NEM tariffs, not the non-NEM counterparts. Therefore, a DPV adopter automatically incurs a fixed increase in their electric bill upon adopting a PV system of any size, in addition to the changes caused by the decreased energy consumption charge and value earned by their generation. This differs from tariff changes elsewhere in the United States, where increases in fixed charges have been applied to all customers, not just the ones with DPV.

To understand better the relative influence of each component within the NEM tariffs, the bill savings and simple payback periods were calculated for a representative residential customer located in NV Energy's southern service territory. We evaluated system finances for a southfacing roof plane with a slope of 20 degrees. The load profile was generated in a previous NREL effort using EnergyPlus with inputs aligned with the Building America House Simulation Protocols (Hendron and Engebrecht 2010). ${ }^{24}$ This customer was selected to have an aboveaverage consumption $(18,000 \mathrm{kWh}$ /year, as compared to an average housing unit consumption of $10,345 \mathrm{kWh} /$ year for Nevada and New Mexico [EIA 2009]) to show a greater range of PV system sizes. However, the customer was not large enough to subscribe to NV Energy's Large Residential Service tariff, which requires $30,000 \mathrm{kWh} /$ year of consumption.

We analyzed the project's finances under four tariffs, shown in Table 2. The first (Full-retail NEM) is the previous tariff for residential customers in the Las Vegas region - the Residential Service (RS) tariff-which had full-retail NEM. ${ }^{25}$ The second (Enacted Tariff) is the newly enacted RS tariff for NEM customers, modeled at the levels at the end of its scheduled transition. ${ }^{26}$ The third and fourth (Increased Fixed Charge and Reduced Export Credit) are hypothetical tariffs designed to each explore a single component of the Enacted Tariff. They each are the same as the original Full-retail NEM tariff, except for having either an increased fixed charge or reduced credit for exported electricity, respectively.

\footnotetext{
${ }^{24}$ This load profile can be accessed at http://en.openei.org/datasets/dataset/commercial-and-residential-hourly-loadprofiles-for-all-tmy3-locations-in-the-united-states. It is the "High" version of the residential profile for the Las Vegas TMY3 station.

${ }^{25}$ Historically, NV Energy subtracted several small public purpose charges from the credit that customers received for exported energy. We retained these charges in our modeling, and therefore any mention of nominally full-retail net metering is actually retail less the public purpose charges.

${ }^{26}$ The phased transition results in a gradual change in the financial performance of DPV. We modeled the end levels to explore the impact of the new NEM tariff design, as opposed to an intermediate step, which would only reflect a partial change.
} 
Table 2. Tariff Structures for Simple Payback Analysis

\begin{tabular}{|c|c|c|c|}
\hline & $\begin{array}{l}\text { Fixed Charge } \\
\text { (\$/mo.) }\end{array}$ & $\begin{array}{l}\text { Energy Consumption } \\
\text { Rate ( } \$ / \mathbf{k W h})\end{array}$ & $\begin{array}{l}\text { Value of Exported } \\
\text { Electricity }(\$ / \mathrm{kWh})\end{array}$ \\
\hline Full-retail NEM & 12.75 & 0.11289 & 0.11137 \\
\hline Enacted Tariff & 38.51 & 0.10179 & 0.02649 \\
\hline Increased Fixed Charge & 38.51 & 0.11289 & 0.11137 \\
\hline Reduced Export Credit & 12.75 & 0.11289 & 0.02649 \\
\hline
\end{tabular}

Note that the hypothetical tariffs were designed to explore how project finances are influenced by the various components. We are not implying that these hypothetical tariffs were viable alternatives, or that they reflect the cost of service. Rather, they are an exploration of the impact of changing a particular component of the tariffs to better understand how that element influences the financial performance of DPV under the Enacted Tariffs.

Figure 9 (at the end of this section) shows the bill savings and simple payback trends for these four tariffs. For the sake of having transparent financial assumptions, the simple payback was determined for a cash purchase system. This differs from the assumptions made by the dGen model elsewhere in this analysis, which assume customers finance their systems. Additionally, we make a simplifying assumption that the total installed cost is a constant $\$ 3.12 / \mathrm{W}$, regardless of system capacity. ${ }^{27}$ In reality, reported data on installed system costs confirm economies of scale for residential systems (Barbose and Darghouth 2015).

The figure shows the first year annual bills savings, simple payback period, and fraction of PV generation that is exported, over a range of PV system sizes. The range goes up to $10.7 \mathrm{~kW}$, which is the capacity that would generate $100 \%$ of this customer's total annual energy consumption. The annual bill savings are calculated as the difference between the cost of electricity with PV, under the given tariff, and the cost of electricity without PV under the Fullretail NEM tariff.

First examining the Full-retail NEM tariff, we can see it resulted in annual bill savings that were nearly linear with system size, as the exported electricity is credited at retail value less the small public purpose charges. This results in a nearly constant simple payback period of 13 years, regardless of system size.

Next, we considered the hypothetical tariff that had the increased fixed charges but still credited excess generation at the same rate as consumption less the public purpose charges. We can see that the bill savings increase linearly with system size, in a manner that is similar to the Fullretail scenario, but are offset by $\$ 309.12$, which is the cost incurred upon DPV adoption by the difference in fixed charges between the NEM and non-NEM tariffs. The result is a significantly different payback period curve than that of the Full-retail NEM tariff. At small system sizes, the increased fixed charges result in lengthy payback periods. As the system size increases and the

\footnotetext{
${ }^{27}$ The installed cost was taken as the estimated installed cost for a 5-kW residential system in the first quarter of 2015 (Feldman et al. 2015). The value is only intended as an approximation, as this analysis is primarily focused on the relative influences of the tariff components.
} 
fixed-charge increase becomes smaller relative to the total bill savings, the payback period improves and converges toward the payback period of the Full-retail NEM tariff.

Next, we considered the hypothetical tariff that has decreased value for exported credit but retained the lower fixed charges. It has the same bill savings as the Full-retail NEM tariff until $1.7 \mathrm{~kW}$, at which point the system starts exporting electricity during each hourly netting period for the significant reduced rate of 2.6 cents $/ \mathrm{kWh}$. As the system size under this tariff further increases the bill savings taper off due to greater quantities of the generation being valued at the reduced credit. The fraction of the DPV energy exported is shown in the lower panel of Figure 13, where imports and exports are netted on an hourly basis. A 2-kW system would export approximately $6 \%$ of its annual generation, whereas a $10.7-\mathrm{kW}$ system sized to meet $100 \%$ of annual consumption would export $56 \%$. The increasing percentage of generation being exported resulted in a payback period curve that became steadily less favorable as system sizes increased.

The trends of the two hypothetical tariffs allow us to conclude that each component of the actual tariff design has its strongest influence at a different size range. The increased fixed charge suppresses the financial performance of small systems, whereas the reduced export credit does the same for larger systems.

We can see the result of combining the two components in the new NEM tariff (Enacted Tariff). The bill savings are significantly lower than under the Full-retail NEM tariff. In particular, for systems under $0.6 \mathrm{~kW}$, installing PV would actually raise the owner's annual electric bill, as the on-site generation would be insufficient to offset the bill increase incurred by the higher fixed charge. As the system size increases, the increase in bill savings with each kilowatt decreases, as a greater proportion of the DPV generation is exported as opposed to self-consumed. For this particular customer, a 3.4-kW system has the lowest simple payback period under the new tariff; however, the combination of the tariff component changes result in a payback of 22.5 years.

The payback period trends shown are illustrative of the impact of each tariff's structure, but the exact magnitudes should not be interpreted as the current performance of DPV in Nevada - in reality, the tariff will transition to the enacted structure over time, during which the price of PV and cost of electricity will continue to change. 


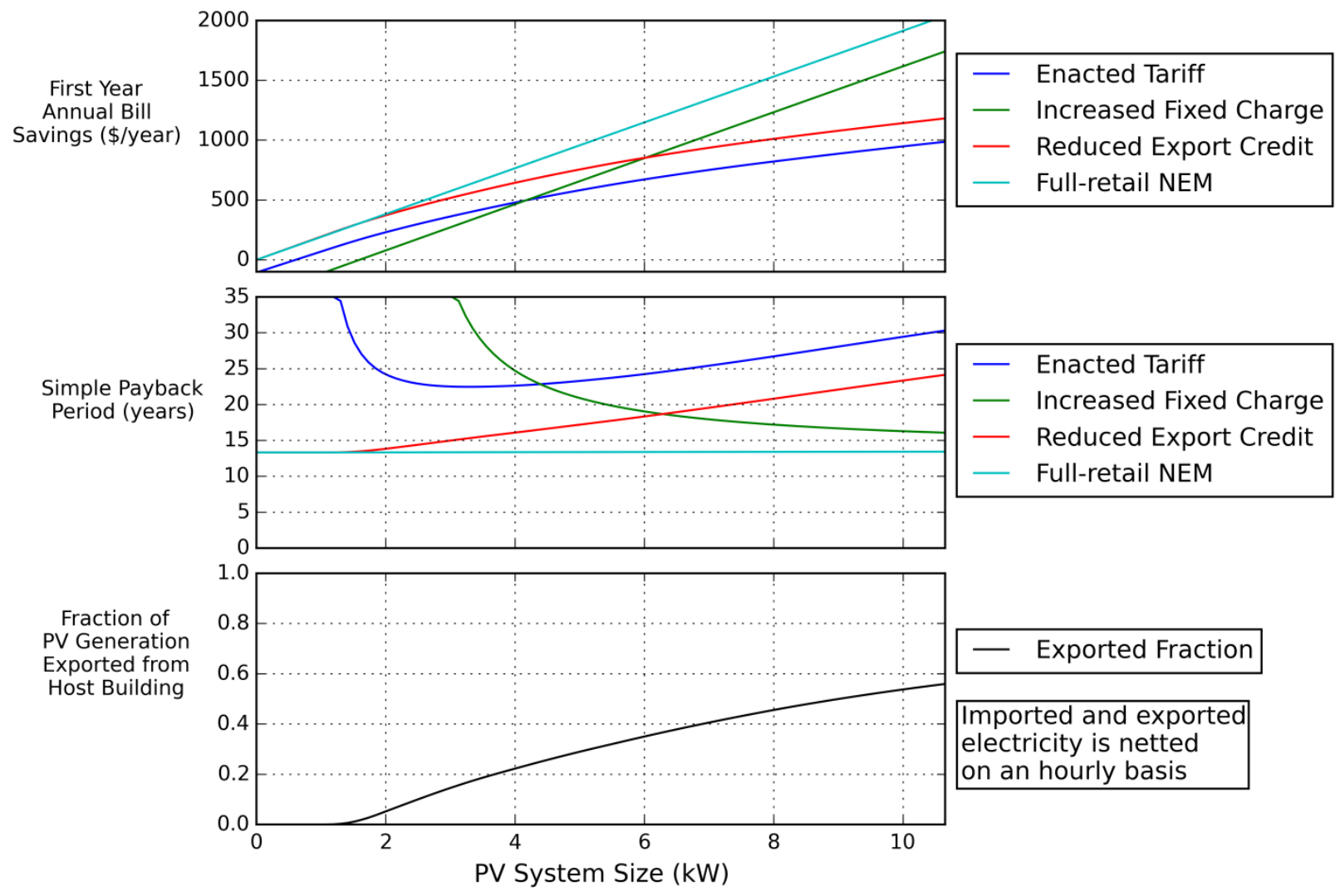

Figure 9. Financial performance of DPV systems under four different tariffs 


\section{Statewide Projections}

In this section, we explore projections of DPV adoption and energy generation. We used NREL's customer adoption model dGen to analyze two scenarios: (1) projections of DPV adoption under the new NEM tariffs (Enacted Tariffs) and (2) the counter-factual Full-retail NEM scenario where the original tariffs remained, with full-retail NEM and no aggregate capacity limit on DPV deployment. To characterize the sensitivity of each of the results to different technology costs, we modeled two different PV price trajectories for each of the two tariff conditions. The results produced by these sensitivities are not intended to exhaustively bound the possible space of DPV deployment, but rather illustrate the response of each of the impact metrics to a change in the financial performance of DPV.

\subsection{Impact on DPV Deployment}

dGen's projections of cumulative installed DPV capacity in NV Energy's territories are shown in Figure 10. As discussed above, the combined effects of the tariff component changes significantly suppressed the financial performance of DPV, lowering adoption rates under the new tariffs. In those scenarios, 290-363 MW of cumulative DPV are projected in 2030 across all residential, commercial, and industrial customers. For reference, $226 \mathrm{MW}$ of DPV had been installed in Nevada as of the end of the second quarter of 2016, with 93 MW installed in 2015 alone (GTM Market Insights). If PV prices dropped rapidly prior to the expiration of the federal investment tax credit, 1,280 MW of DPV were projected to have been adopted under the previous full-retail NEM tariffs. ${ }^{28}$ We can see a pause in adoption in the year 2022 in all of the scenarios, which was caused by the ITC decreasing from $22 \%$ to $0 \%$ for residential customers at that time. If PV prices declined at a moderate pace, adoption was projected to resume in later years, reaching 1,100 MW in 2030 under full retail NEM. The continued installation of systems during 2016 - after the new NEM tariffs were enacted - is largely due to contracts that were signed prior to the tariff changes. Additionally, the six megawatts of capacity that are allowed to subscribe to the pre-2016 tariffs are projected to do so by the end of 2017 in the Enacted Tariffs scenarios.

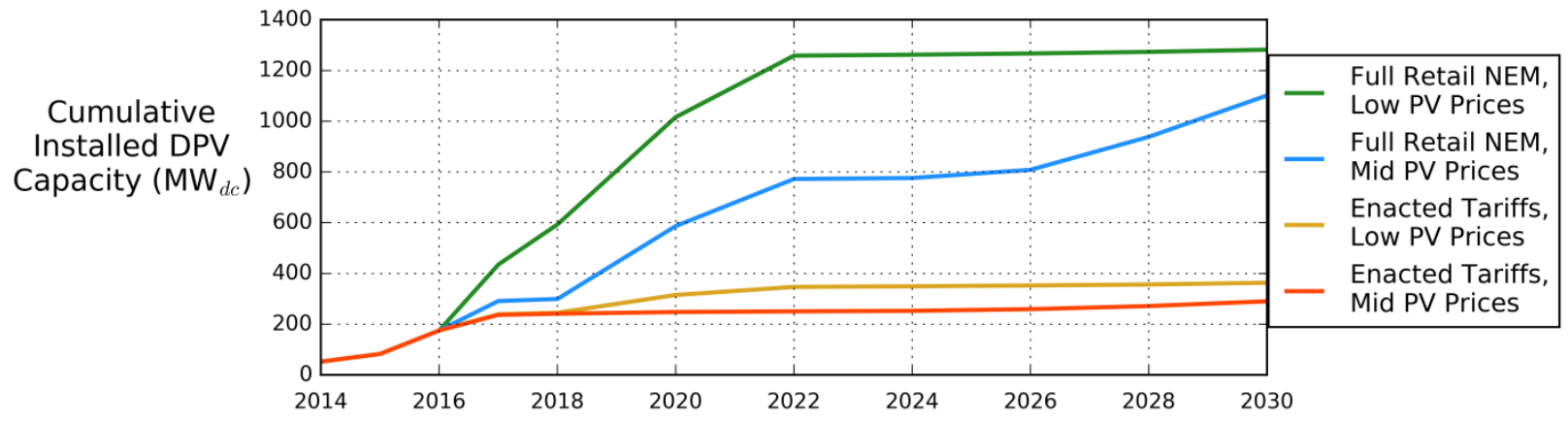

Figure 10. Cumulative installed DPV capacity projections

\footnotetext{
${ }^{28}$ The federal investment tax credit is scheduled to phase down to $0 \%$ for residential and $10 \%$ for non-residential systems by 2022. Because of the "commence construction" clause, dGen assumes non-residential deployment can obtain the credit of the year prior to the completion of its construction.
} 


\subsection{Impact on Energy Generation and Exports from DPV}

As we can see in Figure 11, between 0.5 and $0.6 \mathrm{TWh} /$ year of electricity generation is projected from DPV in 2030 under the new tariffs. For reference, that is $1.4 \%-1.8 \%$ of the $34.2 \mathrm{TWh}$ of electricity projected to be sold by NV Energy in 2030. In contrast, under the Full-retail NEM tariffs and without aggregate capacity limits, we projected between 1.9 and $2.2 \mathrm{TWh} /$ year of electricity generation from DPV in 2030 , which is $5.7 \%-6.5 \%$ of the projected sales of electricity in $2030 .^{29}$

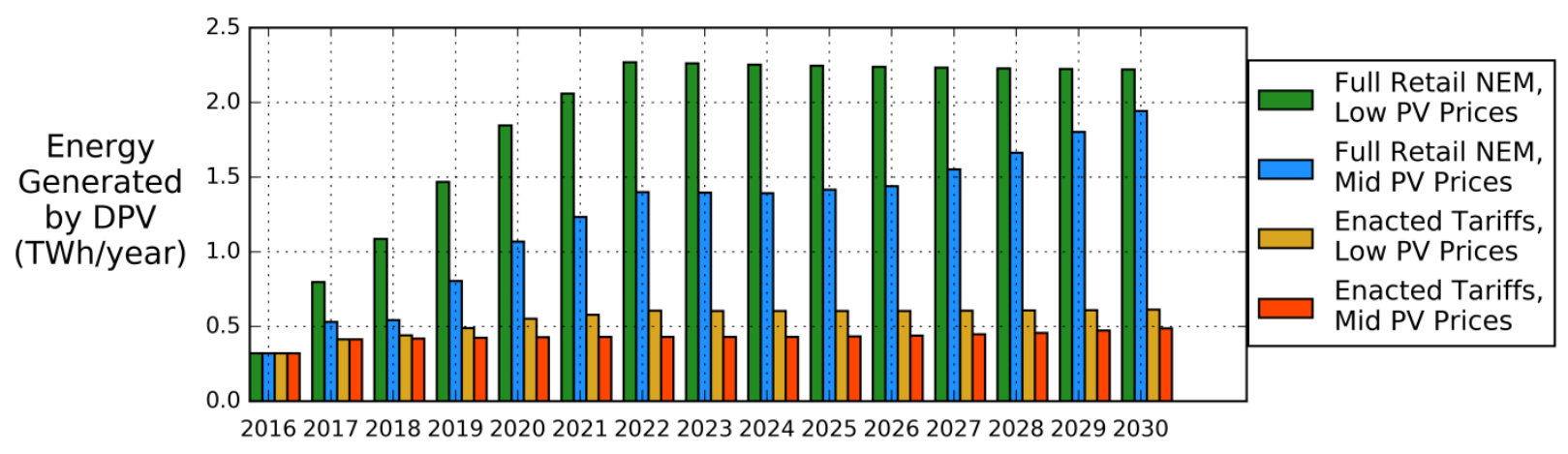

Figure 11. Projections of annual energy generated by DPV systems

As with nearly every utility in the United States, NV Energy's residential tariffs have no demand charges and higher energy consumption charges as compared to commercial and industrial tariffs. This results in DPV generally having better financial returns for a residential customer than a non-residential customer. This situation held under both sets of tariffs of our analysis, and accordingly the residential sector saw the majority of DPV adoption in all scenarios.

In all the scenarios, a significant fraction of DPV generation was exported from the host building. As we can see in Figure 12, we projected 0.9-1.1 TWh/year of exported electricity in 2030 in the Full-retail NEM scenarios. Under the Enacted Tariffs, between $0.1-0.2 \mathrm{TWh} / \mathrm{year}$ of exported electricity is projected. The quantity of exports under the new tariffs remains nearly constant over time as new capacity makes up for the degradation of existing systems.

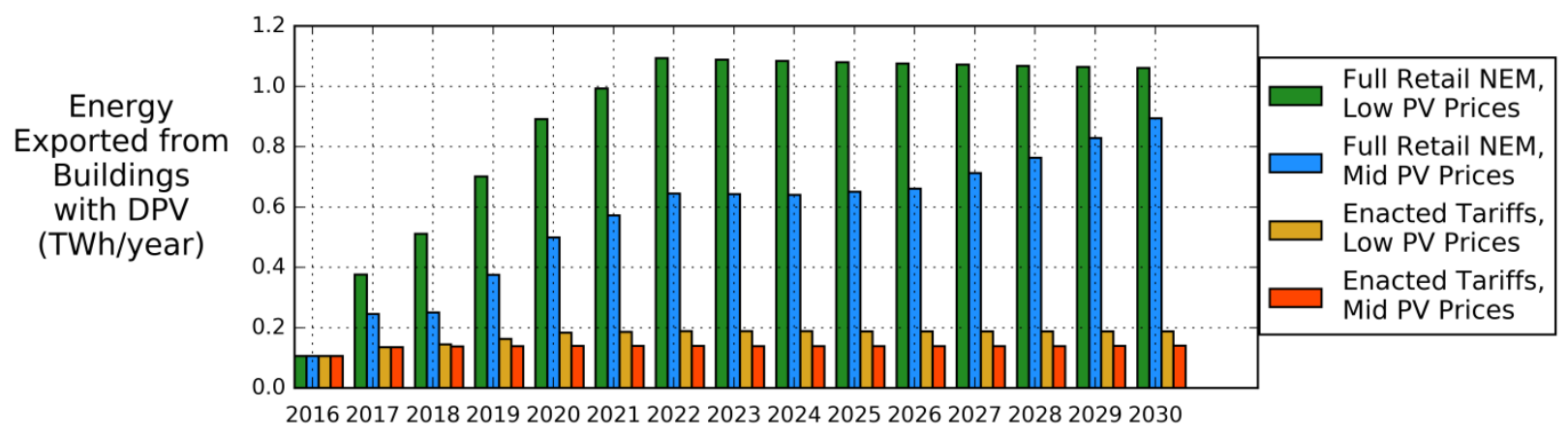

Figure 12. Projections of energy exported from DPV host buildings

\footnotetext{
${ }^{29}$ This simple projection of the electricity to be sold by NV Energy in 2030 is obtained by increasing the $29.21 \mathrm{TWh}$ that NV Energy reported selling in 2014 by the sector-weighted 17\% increase in the consumption of electricity that the EIA AEO 2015 reference case projects for the Mountain Census Division from 2014 to 2030.
} 


\subsection{Impact on Gross Revenue Collection from DPV Customers}

The final metric we explored is the decrease in NV Energy's gross revenue from bill collection from DPV customers, as compared to what would have been collected if those same customers had not adopted PV. This metric could also be considered the total annual bill savings realized by DPV adopters in each scenario. This metric is not an assessment of the change in profit for NV Energy. Assessing the profit implications would require estimates of what capacity would otherwise be built and at what cost, the valuation of DPV's variable generation in the resource planning of a utility, the increase or decrease in infrastructure costs, and a detailed analysis of how the DPV generation would influence the fuel and operational costs of the rest of the generation fleet. The net influence of the DPV systems on all of NV Energy's customers is particularly sensitive to the difference between the cost of DPV energy and other renewable energy sources, because Nevada's RPS and Senate Bill 123 both require set quantities of renewable energy to be procured.

The decrease in gross revenue for the four scenarios is shown in Figure 13 (next page). The decrease was projected to have reached a value of \$222-\$255 million (in real 2016 dollars) per year in 2030 in the scenarios where full-retail NEM was continued, no NEM aggregate capacity limit was enforced, and no additional rate restructuring was performed. ${ }^{30}$ For reference, that is $6.5 \%-7.5 \%$ of the $\$ 3,395$ million (real 2016 dollars) of total gross revenue projected to be collected by NV Energy in 2030 for the sale of electricity. ${ }^{31}$ Note that the exported energy credits never result in payment from NV Energy to a DPV customer, as systems are limited to producing no more than $100 \%$ of annual consumption and unspent credits are carried forward into the following months.

In the scenarios modeling the currently enacted tariffs the reduction in gross revenue collected ranged from $\$ 39$ to $\$ 48$ million per year in 2030 , which is mostly due to systems grandfathered under the previous NEM tariffs. The annual reduction in gross revenue collected peaked in 2024 at $\$ 49$ million per year. The value declined after that because of both decreasing compensation for non-grandfathered customers as well as the degradation of existing systems.

\footnotetext{
${ }^{30}$ The decrease in gross revenue is a combination of PV's influence on energy consumption and reduced demand charges, as well as the value of credit earned for exported generation.

${ }^{31}$ NV Energy reported collecting \$3056.5 million from the sale of electricity in 2014 (FERC 2014A, 2014B). A projection of 2030 gross revenue collection was estimated by multiplying the projected change in price of electricity and the projected change in electricity consumption of each of the residential, commercial, and industrial sectors, and combining them into a weighted average increase. The electricity price and consumption projections are taken from the 2015 EIA AEO reference case for the Mountain Census Division (EIA 2015).
} 


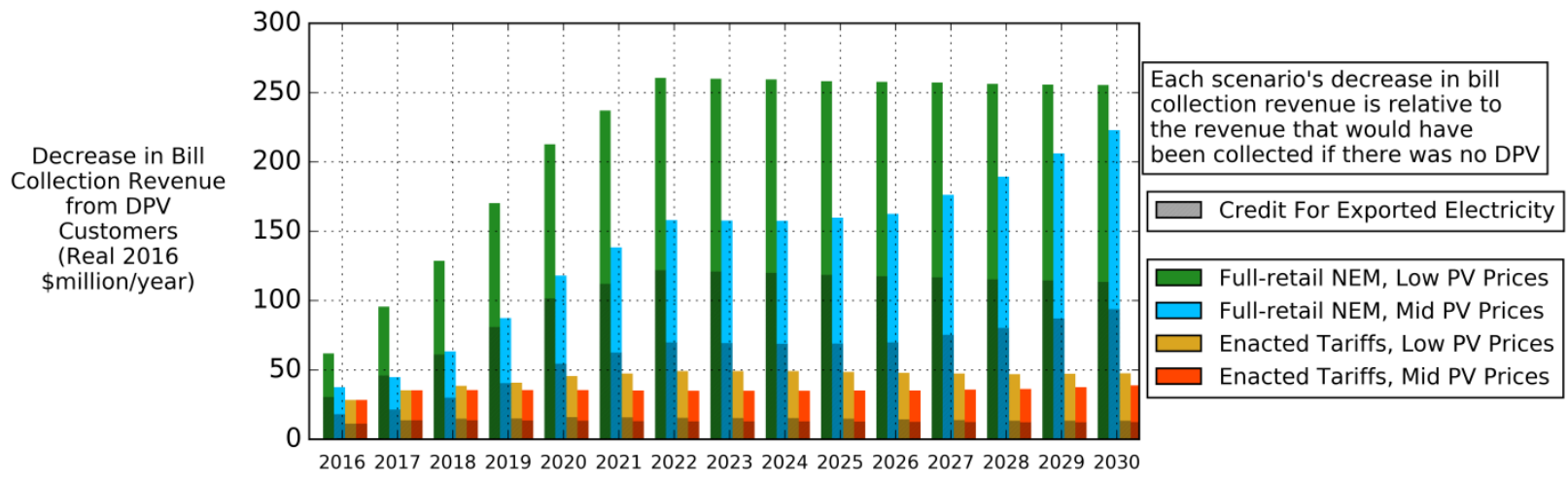

Figure 13. Projections of decrease in gross utility bill collection revenue from DPV customers

The result of dividing the reduction in gross revenue by the amount of generation could be taken as the average cost at which NV Energy would procure this particular resource. For example, the Enacted Tariffs scenario with low PV prices saw 0.61 TWh generated and a $\$ 48$ million reduction in gross revenue in 2030, which equates to an effective cost of 7.9 cents $/ \mathrm{kWh}$ of procured DPV generation. The 7.9 cents $/ \mathrm{kWh}$ is the average compensation across both grandfathered systems and new systems without full-retail NEM. In contrast, the Full-retail NEM scenario with low PV prices saw 2.2 TWh of generation and a gross revenue reduction of \$255 million, which equates to an effective cost of 11.6 cents/kWh of procured DPV generation.

Although useful for a rough characterization of the relative costs of procurement, in most cases it would be inappropriate to use only this metric to compare the cost of DPV generation with other energy sources without considering other values. For instance, in comparing DPV with generation from utility-scale PV, the DPV has additional value of reduced transmission and distribution losses that are not reflected by the simple calculation above. Conversely, comparing this cost of DPV generation against the cost of generation from a natural gas fired turbine would not reflect the inability to dispatch the DPV resource. 


\section{Conclusions}

NV Energy's changes to their NEM tariffs increase fixed charges and reduce credit for exported generation for DPV systems. Our analysis of these effects on a representative residential customer found that an increased fixed charge lengthens the payback period for a small system, and a reduced credit for exported generation does the same for large systems. In its ultimate form, NV Energy's new NEM tariff was estimated to lengthen the simple payback period for a representative residential DPV system from approximately 13 years to more than 22 years.

The longer payback periods under the new tariffs resulted in projections of reduced DPV adoption; total capacity in 2030 was projected to reach $290 \mathrm{MW}-363 \mathrm{MW}$, with $226 \mathrm{MW}$ having already been installed at the end of the second quarter of 2016. In contrast, if full-retail NEM had continued and no aggregate capacity limits were enforced, DPV deployment was projected to have increased from the $226 \mathrm{MW}$ seen halfway through 2016 to $1,100 \mathrm{MW}-1,280 \mathrm{MW}$ at the end of 2030, depending on the rate at which PV prices declined. In these scenarios, DPV energy penetration accounts for an estimated $5.7 \%-6.5 \%$ of the projected total sales of electricity by NV Energy in 2030 . With over $95 \%$ of that generation coming from the residential sector, the local energy penetration levels on individual distribution feeders would be even higher.

The impact on the gross revenue collection from DPV customers is correspondingly larger under the Full-retail NEM scenario. The gross revenue collection in 2030 for those scenarios was projected to be $\$ 222$ million-\$255 million (in real 2016 dollars) per year less than if there was no DPV. For reference, that is $6.5 \%-7.5 \%$ of the $\$ 3,395$ million (real 2016 dollars) of total gross revenue projected to be collected by NV Energy in 2030 for the sale of electricity. Under the Enacted Tariff scenarios, the decrease in gross revenue collection relative to no DPV is estimated at $\$ 39$ million- $\$ 48$ million per year in 2030 , which is $1.1 \%-1.4 \%$ of NV Energy's projected total gross revenue from the 2030 sale of electricity.

These metrics focus on describing the impact of the tariff changes on the financial performance and adoption of rooftop PV. Although they are illustrative of the impact that changes to NEM policy can have on this sector, they represent an incomplete picture of the motivation for and implications of tariff changes. Other states that are weighing similar tariff design issues could use this methodology in combination with a broader suite of tools that evaluate impacts on the utilities themselves, other customers' electric bills, total renewable energy generation, job creation, and other metrics of interest. 


\section{References}

Barbose, Galen, and Naïm Darghouth. 2015. Tracking the Sun VIII: An Historical Summary of the Installed Price of Photovoltaics in the United States from 1998 to 2014. Berkeley, CA: Lawrence Berkeley National Laboratory.

Barbose, Galen, John Miller, Ben Sigrin, Emerson Reiter, Karlynn Cory, Joyce McLaren, Joachim Seel, Andrew Mills, Naïm Darghouth, and Andrew Satchwell. 2016. On the Path to SunShot: Utility Regulatory and Business Model Reforms for Addressing the Financial Impacts of Distributed Solar on Utilities. Golden, CO: National Renewable Energy Laboratory. NREL/TP-6A20-65670; LBNL-1004371.

Bass, F. “A New product Growth Model for Product Diffusion.” Management Science 15(5, 1969):215-227.

Bird, Lori, J. McLaren, J. Heeter, C. Linvill, J. Shenot, R. Sedano, and J. Migden-Ostrander. Regulatory Considerations Associated with the Expanded Adoption of Distributed Solar. 2013. Golden, CO: National Renewable Energy Laboratory. NREL/TP-6A20-60613.

De Martini, Paul, Lorenzo Kristov, and Lisa Schwartz. 2015. Distribution Systems in a High Distributed Energy Resources Future. Berkeley, CA: Lawrence Berkeley National Laboratory. LBNL-1003797.

Denholm, Paul, Easan Drury, and Robert Margolis. The Solar Deployment System (SolarDS) Model: Documentation and Sample Results. 2009. Golden, CO: National Renewable Energy Laboratory. NREL/TP-6A2-45832.

DOE (U.S. Department of Energy). 2012. SunShot Vision Study: February 2012. NREL/BK520047927. DOE/GO-102012-3037.

DSIRE 2016A. "Nevada Net Metering." http://programs.dsireusa.org/system/program/detail/372. Accessed June 2016.

DSIRE 2016B. "Energy Portfolio Standard." http://programs.dsireusa.org/system/program/detail/373. Accessed June 2016.

EIA (U.S. Energy Information Administration). 2009. "Residential Energy Consumption Survey (RECS).” Washington, D.C.: U.S. Energy Information Administration.

- 2012. "Commercial Building Energy Consumption Survey (CBECS).” Washington, D.C.: U.S. Energy Information Administration.

—. 2013. "Updated Capital Cost Estimates for Utility Scale Electricity Generating Plants." U.S. Energy Information Administration.

- 2015. "Electric Power Sales, Revenue, and Energy Efficiency Form EIA-861 Detailed Data Files.” Washington, D.C.: U.S. Energy Information Administration. 
- 2015. Annual Energy Outlook. Washington, D.C.: U.S. Energy Information Administration. DOE/EIA-0383(2015).

Feldman, David, Galen, Robert Margolis, Mark Bolinger, Donald Chung, Ran Fu, Joachim Steel, Carolyn Davidson, and Ryan Wiser. 2015. Photovoltaic System Pricing Trends - Historical, Recent, and Near-Term Projections: 2015 Edition. Golden, CO: National Renewable Energy Laboratory. NREL/PR-6A20-64989.

FERC Form No.1/3-Q, Nevada Power Company, 2014, d/b/a NV Energy

FERC Form No.1/3-Q, Sierra Pacific Power Company, 2014, d/b/a NV Energy

Frew, Bethany, Trieu Mai, Venkat Krishnan, and Scott Haase. Utility-Scale Solar Deployment Scenarios of the Western United States: Implications for Solar Energy Zones in Nevada. 2016. Golden, CO: National Renewable Energy Laboratory. NREL/TP-6A20-65668.

Gagnon, Pieter, Robert Margolis, Jennifer Melius, Caleb Phillips, and Ryan Elmore. 2016. Rooftop Photovoltaic Technical Potential in the United States: A Detailed Assessment. Golden, CO: National Renewable Energy Laboratory. NREL/TP-6A20-65298.

Gilman, Paul, and Aron Dobos. 2012. System Advisor Model, SAM 2011.12.2. 2: General Description. Golden, CO: National Renewable Energy Laboratory. NREL/TP-6A20-53437.

GTM (Greentech Media Research) and SEIA (Solar Energy Industries Association). 2016. "U.S. Solar Market Insight Report 2016 Q3.” Solar Energy Industries Association, SEIA.

Hendron, Robert, and Cheryn Engebrecht. 2-10. Building America House Simulation Protocols. Golden, CO: National Renewable Energy Laboratory. NREL/TP-550-49426.

Hledik, Ryan, Jim Lazar, and Lisa Schwartz. 2016. Distribution System Pricing with Distributed Energy Resources. Berkeley, CA: Lawrence Berkeley National Laboratory. LBNL-1005180.

Kann, Shayle. "How to Find Compromise on Net Metering." Greentech Media. April 27, 2016.

King, Angus. 2015. The Free Market Energy Act of 2015.

Mai, T., R. Wiser, D. Sandor, G. Brinkman, G. Heath, P. Denholm, D. J. Hostick, N. Darghouth, A. Schlosser, and K. Strzepek. 2012. Exploration of High-Penetration Renewable Electricity Futures. Vol. 1 of Renewable Electricity Futures Study. Golden, CO: National Renewable Energy Laboratory, NREL/TP-6A20-52409-1.

Muro, Mark, and Devashree Saha. Rooftop Solar: Net metering is a Net Benefit. Brookings Paper, May 23, 2016.

North Carolina Clean Energy Technology Center. 2016. The 50 States of Solar: Q1 2016 Quarterly Report.

NREL (National Renewable Energy Laboratory). 2015. Annual Technology Baseline. Golden, CO: National Renewable Energy Laboratory.

http://www.nrel.gov/analysis/data tech_baseline.html. 
NV Energy RenewableGenerations. 2015. RenewableGenerations Monthly Report. August. Reno, NV: NV Energy RenewableGenerations.

https://nvenergy.com/renewablesenvironment/renewablegenerations/documents/RenGenAugust-2015-Monthly-Report.pdf

NV Energy RenewableGenerations. 2016. RenewableGenerations Monthly Report. July. Reno, NV: NV Energy RenewableGenerations.

https://nvenergy.com/renewablesenvironment/renewablegenerations/documents/monthlyreport/R enGen-July-2016-Report.pdf

Paidipati, J., L. Frantzis, H. Sawyer, and A. Kurrasch. 2008. Rooftop Photovoltaics Market Penetration Scenarios. Golden, CO: National Renewable Energy Laboratory. NREL/SR-58142306.

Palmintier, Bryan, Robert Broderick, Barry Mather, Michael Coddington, Kyri Baker, Fei Ding, Matthew Reno, Matthew Lave, and Ashwini Bharatkumar. 2016. On the Path to SunShot:

Emerging Issues and Challenges in Integrating Solar with the Distribution System. Golden, CO:

National Renewable Energy Laboratory. NREL/TP-5D00-65331; SAND2016-2524.

Price, Snuller, Katie Pickrell, Jenya Kahn-Lang, Zachary Ming, and Michele Chait. 2014. Nevada Net Energy Metering Impacts Evaluation. San Francisco, CA: Energy and

Environmental Economics, Inc.

Price, Snuller, Zachary Ming, Alison Ong, and Sheridan Grant. 2016. Nevada Net Energy Metering Impacts Evaluation 2016 Update. San Francisco, CA: Energy and Environmental Economics, Inc.

Rogers, Everett. Diffusion of Innovations, 5th ed. (2003)

Sigrin, Ben, and Easan Drury. 2014. "Diffusing into New Markets: Economic Returns Required by Households to Adopt Rooftop Photovoltaics." AAAI Fall Symposium Series.

Sigrin, Benjamin, Michael Gleason, Robert Preus, Ian Baring-Gould, and Robert Margolis. 2016. The Distributed Generation Market Demand Model (dGen): Documentation. Golden, CO: National Renewable Energy Laboratory. NREL/TP-6A20-65231.

SolarCity and NRDC (Natural Resources Defense Council). 2016. Distributed Energy Resources in Nevada.

Wilcox, S., and W. Marion. 2008. Users Manual for TMY3 Data Sets. Golden, CO: National Renewable Energy Laboratory. NREL/TP-581-43156.

Wood, Lisa, Ross Hemphill, John Howat, Ralph Cavanagh, Severin Borenstein, Jeff Deason, and Lisa C. Schwartz. 2016. Recovery of Utility Fixed Costs: Utility, Consumer, Environmental and Economist Perspectives. Berkeley, CA: Lawrence Berkeley National Laboratory. LBNL-1005742. 